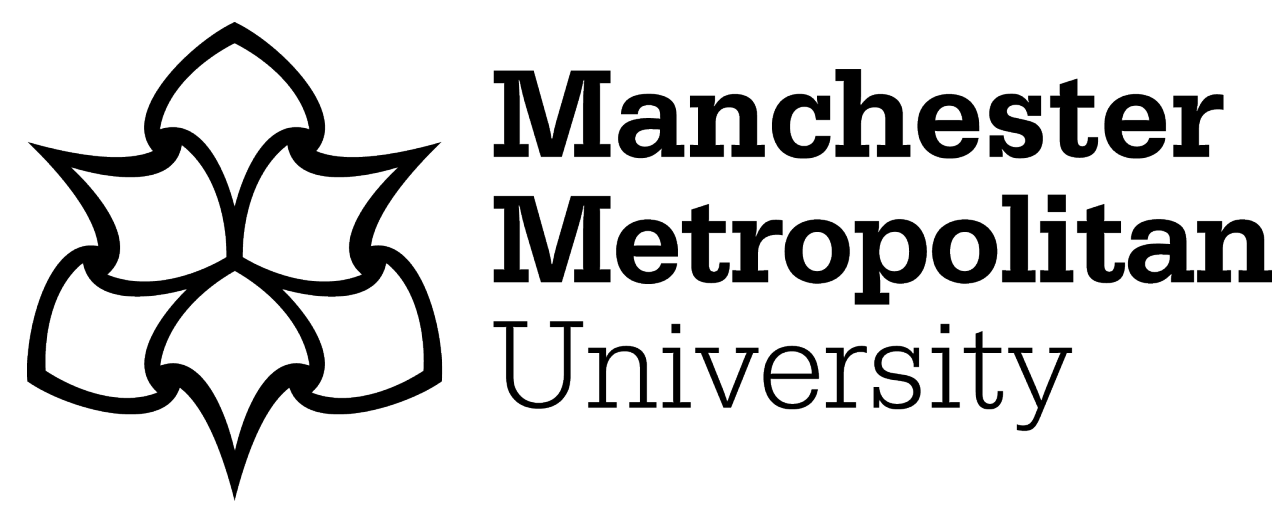

Shepherd, Todd, Winwood, Keith, Venkatraman, Prabhuraj, Alderson, Andrew and Allen, Thomas ORCID logoORCID: https://orcid.org/0000-00034910-9149 (2020) Validation of a Finite Element Modelling Process for Auxetic Structures under Impact. physica status solidi (b), 257 (10). p. 1900197. ISSN 0370-1972

Downloaded from: https://e-space.mmu.ac.uk/625038/

Version: Accepted Version

Publisher: Wiley

DOI: https://doi.org/10.1002/pssb.201900197

Please cite the published version 


\section{Validation of a Finite Element Modelling Process for Auxetic Structures under Impact}

Todd Shepherd, Keith Winwood, Prabhuraj Venkatraman, Andrew Alderson and Thomas Allen*

T. Shepherd, Dr. K. Winwood, Dr. P. Venkatraman, Dr. T. Allen

Sports Engineering Research TEAM, Manchester Metropolitan University, Chester Street, Manchester, M15 6BH, UK

E-mail: todd.shepherd@stu.mmu.ac.uk

Prof. A. Alderson

Materials and Engineering Research Institute, Sheffield Hallam University, Sheffield, S1 1WB, UK

Keywords: auxetic, finite element modelling, sporting protective equipment, additive manufacturing, validation

Auxetic materials behave unconventionally under deformation, which enhances material properties such as resistance to indentation and energy absorption. Auxetics, therefore, have the potential to enhance sporting protective equipment. This study explores finite element modeling, additive manufacturing and impact testing of three auxetic lattices, and a conventional equivalent, with a view to advance auxetic implementation within sports equipment. The lattices are modeled and impacts are simulated between $1 \mathrm{~J}$ and $5 \mathrm{~J}$, for flat and hemispherical drop hammers. Simulation outputs, including peak impact force, impact duration, maximum axial strain and Poisson's ratio are compared to experimental results from equivalent impact energies on additively manufactured lattices, using an instrumented drop tower and a high-speed camera. The simulation and experimental results show broad agreement for all lattices and scenarios, demonstrated by comparative force $v$ s time plots and maximum compression images. The benefits of developing and validating finite element models of three auxetic lattices (as well as the conventional honeycomb lattice) under various impact scenarios as a process is discussed, including material characterization of an exemplar thermoplastic polyurethane. Future work could use the models to investigate auxetic lattices further, selecting and tailoring candidates to further explore their potential application to specific personal protective equipment in sport.

This article has been accepted for publication and undergone full peer review but has not been through the copyediting, typesetting, pagination and proofreading process, which may lead to differences between this version and the Version of Record. Please cite this article as doi: $10.1002 /$ pssb.201900197. 


\section{Introduction}

WILEY-VCH

Poisson's ratio $(v)$ is the negative ratio of the lateral to axial strain of a material under compression or tension and ranges between -1 and +0.5 for three-dimensional (3D) isotropic materials, according to elasticity theory, ${ }^{[1]}$ and -1 and +1 for two-dimensional (2D) isotropic materials. ${ }^{[2]}$ Auxetic materials (and structures) have a negative Poisson's ratio (NPR) as they expand laterally when stretched and contract laterally when compressed. ${ }^{[3]}$ Auxetics can have enhanced properties including increased resistance to indentation and increased energy absorption under compression. ${ }^{[4,5]}$ They also exhibit synclastic curvature, ${ }^{[3,6]}$ which could improve the conformability of clothing to the body. Such properties make auxetics ideal candidates for enhancing personal protective equipment (PPE) in sport, ${ }^{[7]}$ such as those used in rugby, ${ }^{[8]}$ American football or snow-sports. ${ }^{[9,10]}$

Head injuries, for example, still frequently occur in sport despite developments in helmet technology and increased user uptake. ${ }^{[11,12]}$ Shear thickening materials are often used in sporting PPE products, such as snowboard back protectors, but their ability to limit impact forces can change with temperature. ${ }^{[13]}$ Approximately 4.5 million people are treated in EU hospitals for sports related injuries annually, ${ }^{[14]}$ at a cost of $€ 2.4$ billion ( $£ 2$ billion), ${ }^{[15]}$ which could be reduced with more effective protection and better regulation. Better fitting, more comfortable and higher performing auxetic PPE has potential to increase participation in sport and improve general wellbeing, both physically and mentally. ${ }^{[16]}$ In addition, a more active population could reduce healthcare costs, particularly as National Health Service providers spent $\sim £ 900$ million on addressing health issues related to physical inactivity in the UK in $2009 / 10 .^{[17]}$ There are also social health benefits of practicing a sport with others. ${ }^{[18]}$ Bailly et al. found that snow-sport participants with an injury that did not concern the head were less likely to be wearing a helmet than those without an injury, ${ }^{[19]}$ challenging the concerns of Wilson that sporting participants who wear PPE take more risks. ${ }^{[20]}$ 


\section{WILEY-VCH}

While auxetic systems can be found in nature, ${ }^{[21]}$ research into these materials has typically focused on man-made products like open-cell foam, which was first manufactured by Lakes using thermo-mechanical techniques that combined compression and heating. ${ }^{[3]}$ Auxetic foam fabrication has also been investigated by Chan and Evans. ${ }^{[4,22]}$ Scarpa et al. were the first to report the dynamic response of auxetic open-cell foam highlighting its potential in crashworthiness applications. ${ }^{[23]}$ More recently, this potential was demonstrated further; open-cell auxetic foam reduced the peak acceleration of drop tower impacts (energies up to $5.6 \mathrm{~J}$ ) by two to three times, when compared to its conventional counterpart. ${ }^{[24]}$ Thin polypropylene shells covering auxetic foam (replicating basic body protection) have reduced peak accelerations between five and ten times, ${ }^{[25,26]}$ when impacted with a hemispherical drop hammer, and absorbed up to three times more energy under quasi-static compression from a stud, ${ }^{[10]}$ when compared to their conventional counterparts. When drop testing a head-form fitted with a sports helmet, Foster et al. reported a reduction of linear accelerations and Gadd Severity Index (up to $44 \%$ for side impacts) ${ }^{[26,27]}$ in using an open-cell auxetic foam liner, rather than the conventional open-cell foam typically used in such helmets.

Temperature and compression gradients can occur during thermo-mechanical fabrication of opencell auxetic foam, ${ }^{[25,28]}$ which could result in undesirable inhomogeneous samples when scaled to the larger sizes that are required for developing sporting PPE. Compressing larger foam samples into the mold during fabrication can also result in creases. ${ }^{[22,29]}$ To potentially address these issues, the use of a vacuum pump during the compression stage has been implemented, ${ }^{[30]}$ and the microstructure of the open-cell foam has been subject to specific temperature profiles to effect a more stable auxetic transformation. ${ }^{[31]}$ Other developments in fabrication techniques have also helped improve consistency in large samples of open-cell auxetic foam, such as through-thickness rods to control compression, ${ }^{[32,33]}$ but its application to PPE has not been achieved commercially. 


\section{WILEY-VCH}

Using compressed $\mathrm{CO}_{2}$ in the conversion process has been identified as a potential method to increase sample sizes. ${ }^{[34]}$

Duncan et al. recently explored the effect of heat exposure and volumetric compression during fabrication on the properties of open-cell auxetic foam, ${ }^{[35,36]}$ which could help facilitate investigations into the effect of Poisson's ratio on indentation resistance and impact performance and the application of open-cell auxetic foam in commercial PPE. Closed-cell auxetic foams have been fabricated, ${ }^{[22]}$ with a simpler fabrication process using steam penetration recently developed by Fan et al., ${ }^{[37]}$ although its potential for sporting applications has not been investigated.

There are patents for the application of auxetics in sport related products, ${ }^{[38]}$ while others have resulted in commercially available sports shoes. ${ }^{[39]}$ Another example is the Trust Stealth ${ }^{\mathrm{TM}}$ Helmet Pad System (D3O Technologies, UK) ${ }^{[40]}$ which integrates auxetic structures into the helmet liner padding. To the authors' knowledge, however, there are no peer-reviewed publications that have tested these products. A recent publication by Bliven et al. features a helmet liner (WaveCel Concept ${ }^{[41]}$ for reducing rotational acceleration during oblique impacts. The liner resembles a double arrowhead auxetic structure, ${ }^{[42]}$ although the authors do not refer to the design as auxetic nor provide details of how it was manufactured.

The $2 \mathrm{D}$ re-entrant structure of auxetic materials was the first to be modelled numerically, ${ }^{[43]}$ and was extended to a mechanical model of a 3D structure of rigid rods with elastic hinges to give $v=$ 1. ${ }^{[44]}$ Chiral auxetics are asymmetric structures that are non-superimposable on their mirror image and achieve NPR through node rotation-induced bending of connecting ligaments. ${ }^{[45]}$ Rigid rotating units can have an NPR, dependent on the rotation of connected squares or other shapes (e.g. rectangles, triangles), and this model has been used as an alternative to the re-entrant model in auxetic foams. ${ }^{[46]}$ Computer modeling was used in early auxetic research, with Monte Carlo and 2D lattice models used to demonstrate NPR in anisotropic systems. ${ }^{[47]}$ 


\section{WILEY-VCH}

A route to further facilitating and exploring the uptake of auxetics in sports equipment is through finite element (FE) modeling, which can predict the behavior of materials, structures and products under predetermined conditions and analyze design parameters, such as those in snowboard wrist protectors, ${ }^{[48]}$ helmets and other sporting equipment and facilities. ${ }^{[49-51]}$ FE modelling has been applied to auxetic structures and used to investigate the effect of changing unit-cell geometry on mechanical properties, such as Young's Modulus and Poisson's ratio at low axial strains, ${ }^{[52]}$ and to investigate the effect of altering Poisson's ratio itself on mechanical behavior of auxetic plates. ${ }^{[53]}$ It has also been utilized to analyze the potential of auxetic constituents (e.g. cylinders, sandwichstructures and ellipses) within composite materials, ${ }^{[54]}$ to investigate the effect of unit-cell disorder in hexa/anti-chiral structures on material properties ${ }^{[55]}$ and to illustrate induced NPR in facecentered cubic crystals. ${ }^{[56]}$

FE modelling has been used to investigate auxetic structures under impact scenarios, ${ }^{[57]}$ although these examples use flat plates and a high velocity bullet (150 to $300 \mathrm{~m} / \mathrm{s}$ ), which is different to the impact scenarios typical of sport, in terms of impactor shape, stiffness, mass and velocity. Elsewhere, FE modelling has been used to develop an auxetic jounce bumper in the automotive industry, ${ }^{[58]}$ to produce auxetic stents for medicine and to predict the indentation response of an auxetic foam in an anti-vibration glove. ${ }^{[59,60]}$

The accuracy of FE models should be quantified by comparison against experimental data if they are to be used to develop products such as helmets and other PPE, which requires testing of a physical product or prototype, ${ }^{[61]}$ and was demonstrated for rotating-unit auxetic structures by Slann et al. ${ }^{[62]}$ It is important to validate FE models for scenarios that are representative of those where potential products may be used, such as oblique impacts of helmets or concentrated loads for sporting body padding. ${ }^{[63,64]}$ Once validated, innovative design solutions can be developed and virtually tested using the FE models, based on obtained results and comparison to relevant standards or specific injury criteria. ${ }^{[65-68]}$ Initial designs developed in the FE models can be 


\section{WILEY-VCH}

consequently tested and developed further, as seen with the optimization of a foam liner in equestrian helmets, ${ }^{[67]}$ reducing the requirement for experimental work, which can be timeconsuming and require intricate or specialist test rigs and instrumentation. Validated FE models of auxetic structures could be combined with other FE models when investigating specific areas of interest, such as coupled head-form and helmet models or solid sports ball models, ${ }^{[49,69]}$ allowing specific injury scenarios to be investigated. Overall, FE models can improve our understanding of particular problems; individual components or internal parameters of a design can be isolated and

investigated, ${ }^{[49,66,68]}$ which would not be possible, or at least complicated, experimentally.

Additive manufacturing (AM) can be used to fabricate conventional and auxetic macrostructures as alternatives to foams (microstructures). ${ }^{[0]} \mathrm{AM}$ has been used in a sporting context to design multi-material shin pads, ${ }^{[71]}$ to manufacture cellular structures for potential use in bicycle helmet inner liners and equipment brands have used AM to produce physical models and shoes. ${ }^{[72,73]}$ Specifically designed and intricate auxetic structures can be produced by AM, ${ }^{[74]}$ and used in validation experiments for both FE and analytical models. ${ }^{[58,75]}$ Dual-material AM auxetic structures have also been developed, where a flexible and a stiffer material can be used in different regions of a structure, allowing greater control over its mechanical properties for the designer. ${ }^{[76]}$ These dual-material structures are more complex to manufacture and, through the application of FE modelling, it may be possible to tailor the geometry of a single material structure (e.g. rib thickness and taper) to achieve desirable properties at lower manufacturing complexity. The current state of the art of AM is reported in Ngo et al. and, ${ }^{[77]}$ more specifically for auxetic structures as applicable to sporting PPE, in Duncan et al. ${ }^{[7]}$

The aim of this current work was to develop and validate FE models of auxetic lattices subject to impact at a range of energies ( 1 to $5 \mathrm{~J}$; maximum energy comparable to EN 14120:2003), ${ }^{[78]}$ with a view to progressing their implementation within a sporting PPE context. The work also demonstrates how AM can be used to develop physical prototypes of auxetic lattices that can be 


\section{WILEY-VCH}

used for model validation purposes. The present study uses FE modelling and AM in conjunction to investigate the behavior of auxetic lattices under impact, to potentially advance the application of auxetic materials in a sporting context. The reported validation process is the necessary foundation step taken that can lead to the future development of more finalized and innovative auxetic sporting PPE designs, which should increase the uptake of auxetic materials and structures in sport.

\section{Methods and Materials}

\subsection{Summary}

FE models of three auxetic lattices and a conventional honeycomb lattice were developed for virtual impact testing, using ANSYS ${ }^{\circledR}$ Design Modeler (v18.2), and setup using ANSYS ${ }^{\circledR}$ Engineering Data (v18.2) and ANSYS ${ }^{\circledR}$ Workbench Mechanical (v18.2) (Livermore Software Technology Corporation (LSTC), CA, USA). The front face of each lattice design was sketched and extruded to a depth of $40 \mathrm{~mm}$, resulting in 2.5D lattices (3D objects created by the extrusion of a 2D pattern/face) that could be AM without support material. Simulations were run for all lattices with both a flat and a hemispherical (based on cricket ball diameter of $72 \mathrm{~mm}$ as used in BS 61831:1981) ${ }^{[79]}$ drop hammer, which were assigned velocities corresponding to the required impact energy.

The modeled lattices were converted to .stl files using ANSYS ${ }^{\circledR}$ SpaceClaim (v18.2) and fabricated via AM (Lulzbot® Taz 5 Desktop - fused filament fabrication, Aleph Objects, USA), with print times of $\sim 15$ hours. A thermoplastic polyurethane (TPU) filament (NinjaFlex ${ }^{\circledR}$, Ninjatek, Manheim, PA, USA; blush color; diameter, $3 \mathrm{~mm}$; density $(\rho), 1200 \mathrm{~kg} / \mathrm{m}^{3}$; tensile modulus, 12 $\mathrm{MPa}$; hardness, 85 Shore A; Glass transition, $\left.-35^{\circ} \mathrm{C}\right){ }^{[80]}$ was used as an example material for the validation process, which was selected for its flexibility and durability. AM settings for high print quality (based on visual inspection) were established through pilot prints and used throughout: nozzle diameter, $0.6 \mathrm{~mm}$; print speed, $15 \mathrm{~mm} / \mathrm{s}$; printing temperature, $245{ }^{\circ} \mathrm{C}$; bed temperature, 50 ${ }^{\circ} \mathrm{C}$; layer height, $0.15 \mathrm{~mm}$; travel speed, $200 \mathrm{~m} / \mathrm{s}$; infill orientation, diagonal (Cura software 


\section{WILEY-VCH}

v15.08). A bespoke instrumented drop tower was used to impact test the lattices to validate the FE models (Section 2.4.), ${ }^{[48]}$ with the hammer release height set for each impact energy, assuming no friction in the rail. A range of material characterization techniques (e.g. tension, compression, impact) were assessed for simulating the TPU within the lattice, with the method that produced the best overall agreement with experimental impact testing selected.

\subsection{Characterization of TPU}

Five dog-bone style tensile (ISO 37:2017; ${ }^{[81]}$ gauge length, $25 \mathrm{~mm}$; width, $4 \mathrm{~mm}$; thickness, 2 $\mathrm{mm}$ ) and five cylindrical compressive (BS EN ISO 386-1 (1997); ${ }^{[82]}$ height, $10 \mathrm{~mm}$; diameter, 20 $\mathrm{mm}$ ) TPU samples were fabricated via AM and characterized to support the development of a material model within ANSYS ${ }^{\circledR}$ Mechanical (v18.2). Following initial testing, a further five tensile samples scaled to $150 \%$ of the size outlined in ISO 37:2017 (gauge length $37.5 \mathrm{~mm}$; width, $6 \mathrm{~mm}$; thickness, $3 \mathrm{~mm}$ ) were fabricated via AM to improve strain measurement using Digital Image Correlation (DIC) software (GOM Correlate 2017, GOM GmbH, Braunschweig, Germany). These material samples were used throughout, with measurements of dimensions confirming that the TPU did not pass its elastic limit during testing.

Full-field strain measurements were obtained using DIC, ${ }^{[83]}$ as in previous research with sports equipment and auxetic foam, ${ }^{[33,35,36,84,85]}$ amongst other applications. Speckle patterns were applied to the central region $(37.5 \times 6.0 \mathrm{~mm})$ of the face of the tensile samples prior to testing using matt black acrylic spray paint. A camera (Phantom Miro R110, Vision Research UK Ltd., Bedford, UK; resolution, 1280 x 800 pixels; sample rate, 24 fps; lens, Nikon ${ }^{\circledR}$ AF Nikkor 24-85 mm, f/2.84D IF) was used to film the pattern as the samples were stretched to $50 \%$ of their original length at a strain rate of $0.006 \mathrm{~s}^{-1}$ (Hounsfield HK10S Tensometer; load cell, $100 \mathrm{~N}$; sample rate, $22.5 \mathrm{kHz}$ ). Using Microsoft ${ }^{\circledR}$ Excel, a second order polynomial trend line (selected based on visual inspection) 


\section{WILEY-VCH}

was fitted to plots of lateral $v s$ axial strain, obtained from the video footage using DIC, and differentiated to give the relationship between Poisson's ratio and axial strain.

To investigate the TPU rate dependency, the compressive samples (BSEN ISO 386-1) were tested at the higher strain rates (Instron Universal testing machine, Labtronic 8800 console, $5 \mathrm{kN}$ load cell) of $1 \mathrm{~s}^{-1}, 2 \mathrm{~s}^{-1}, \sim 4 \mathrm{~s}^{-1}, \sim 8 \mathrm{~s}^{-1}$ and, the machine maximum of $\sim 19 \mathrm{~s}^{-1}$ (maximum displacement rate in compression $=\sim 180 \mathrm{~mm} / \mathrm{s}$ ). Further tensile testing was performed at $1 \mathrm{~s}^{-1}$ and $2 \mathrm{~s}^{-1}$, and the maximum achievable strain rate in tension with the samples and the device used (Instron, pneumatic grips, pressure, $3-4$ bar) was $\sim 3 \mathrm{~s}^{-1}$, as undesirable noise was observed in the data at higher rates. The five tensile and compressive samples were cycled to $40 \%$ strain five times (preloads; tensile, $15 \mathrm{~N}$; compressive, $100 \mathrm{~N}$ ), to account for stress softening (Mullins' effect), ${ }^{[86]}$ with the data from the final loading cycle analyzed. Force $v s$ extension data from the testing machine was converted to engineering stress $v s$ engineering strain using the dimensions of each sample, as measured with Vernier calipers (Duratool, D00352).

Stress relaxation tests were performed on two of the compressive samples (from before) at a later date to provide time dependent (viscoelastic) data for the TPU material model (Instron machine, as used previously), as required for simulating lattice response under impact. Prior to relaxation testing, each sample was compressed five times to a strain of either 0.2 or 0.4 (to account for the Mullins' effect). The sample was then compressed to a strain of either 0.2 or 0.4 at a rate of $\sim 12 \mathrm{~s}^{-1}$ $\left(120 \mathrm{~mm} / \mathrm{s} ; \mathrm{t}_{0.2}=0.0176 \mathrm{~s}\right)$ and $\sim 15 \mathrm{~s}^{-1}\left(145 \mathrm{~mm} / \mathrm{s} ; \mathrm{t}_{0.4}=0.0280 \mathrm{~s}\right)$ respectively, where it was then held for 600 seconds, ${ }^{[87]}$ while the decaying force was measured (sample rate, $1.2 \mathrm{kHz}$ ). The factor of ten rule was applied to remove the first $10 \mathrm{t}(\mathrm{s})$ of data after loading $(0.176$ or $0.280 \mathrm{~s}),{ }^{[88]}$ as stress waves generated during loading can result in non-pure viscoelastic behavior at the start of the test. The force data was converted to Young's modulus (E) (in compression) using the sample dimensions and applied strain. Equation (1) was then applied to calculate shear modulus $(G)$, using 


\section{WILEY-VCH}

the Poisson's ratio ( $v$ ) from the tensile tests, with $G v s t$ then plot (as required for the material model input).

$G=\frac{E}{2(1+v)}$

\subsection{Finite element modeling of auxetic lattice impacts}

An auxetic lattice geometry comprising of repeat 'bow tie' re-entrant structures was modeled

(Figure 1) as an initial auxetic prototype to investigate (consisted of seven unit-cells wide and three high). ${ }^{[43,89]}$ A rectangular face $(80.0 \times 46.5 \mathrm{~mm})$ was used as pilot testing showed a squared-faced cuboid lattice $(60 \times 60 \times 20 \mathrm{~mm})$ was prone to buckling under compression. The specific size and shape of the lattice was not deemed crucial, as the focus of this work was to develop and validate FE models, particularly a TPU material model suitable for simulating impact response, whilst exploring the feasibility of using AM for producing prototypes for testing rather than developing a PPE product solution. The re-entrant lattice was split into 123 bodies and given shared topology to obtain a more uniform hexahedral mesh (using default solid elements with constant stress; ELFORM = 1) ${ }^{[90]}$ than when using a continuous geometry $(481,680$ elements; 606,690 nodes $)$. Anti-tetra chiral (735,300 elements; 958,692 nodes, hexahedral mesh), ${ }^{[91]}$ missing-rib/hound's tooth $\left(600,453\right.$ elements; 742,264 nodes, hexahedral mesh) ${ }^{[92]}$ and conventional honeycomb hexagonal honeycomb (531,400 elements; 673,172 nodes, hexahedral mesh) ${ }^{[93]}$ lattices were also modeled (Figure $1 \mathrm{c}-\mathrm{h}$ ) and manufactured using the techniques, model settings and AM settings as for the re-entrant lattice. A maximum element face size of $5 \times 10^{-4} \mathrm{~m}$ was determined from a mesh convergence study for the re-entrant and the same size was used for the hound's-tooth lattice. Maximum element sizes of $4 \times 10^{-4} \mathrm{~m}$ and $3.5 \times 10^{-4} \mathrm{~m}$ was used for the anti-tetra chiral and conventional honeycomb lattices respectively. Relevant metrics were assessed for all meshes; each mesh had a mean aspect ratio value of 1.7 or lower, a mean element quality of 0.85 or higher and a skewness of 0.17 or lower, indicating a good quality mesh. ${ }^{[90,94]}$ Each mesh had at least three 


\section{WILEY-VCH}

elements through each unit-cell wall, preventing shear locking from stiffening the lattices undesirably. ${ }^{[90,94]}$

The unit-cell wall thickness was matched to the re-entrant lattice at $1.5 \mathrm{~mm}$ and the overall lattice dimensions (height, width, depth) were matched closely (re-entrant: mass, 56.0 g; volume (of solid material), $4.67 \times 10^{-5} \mathrm{~m}^{3}$; anti-tetra chiral: mass, $74.7 \mathrm{~g}$; volume, $5.77 \times 10^{-5} \mathrm{~m}^{3}$; hound's-tooth: mass, $80.3 \mathrm{~g}$; volume, $6.56 \times 10^{-5} \mathrm{~m}^{3}$; conventional honeycomb: mass, $38.5 \mathrm{~g}$; volume, $3.27 \times 10^{-5}$ $\mathrm{m}^{3}$ ). The mass of the AM lattices varied from those in the models by $3.1 \mathrm{~g}$ (re-entrant), $9.0 \mathrm{~g}$ (antitetra chiral), $0.9 \mathrm{~g}$ (hound's-tooth) and $0.8 \mathrm{~g}$ (conventional), indicating some inaccuracies in printing. The conventional honeycomb lattice had the lowest mass of the lattices as it was designed using an equivalent cell-angle to the re-entrant lattice $\left(30^{\circ}\right)$ with equivalent dimensions, whilst maintaining whole unit-cells.

To mimic the validation experiments, the flat (steel; diameter, $80 \mathrm{~mm}$; thickness, $10 \mathrm{~mm} ; \rho, 7,850$ $\mathrm{kg} / \mathrm{m}^{3} ; E, 2 \times 10^{11} \mathrm{~Pa} ; v, 0.3$; elements, 5,465; nodes, 6,792; hexahedral mesh) and hemispherical (aluminum alloy; diameter, $0.075 \mathrm{~m} ; \rho, 2,770 \mathrm{~kg} / \mathrm{m}^{3} ; E, 7.1 \times 10^{10} \mathrm{~Pa} ; v, 0.33$; elements, 54,549; nodes, 10,304; tetrahedral mesh with one point constant stress solid elements; ELFORM $=10)^{[90]}$ drop hammers were modeled. The geometries did not include the rail carriage the hammers were attached to (for simplicity), but the densities were adjusted (flat, $31,990 \mathrm{~kg} / \mathrm{m}^{3}$; hemisphere, 19,708 $\mathrm{kg} / \mathrm{m}^{3}$ ) to match the total experimental mass (flat, $1.60 \mathrm{~kg}$; hemisphere, $1.92 \mathrm{~kg}$ ). A base plate was also modeled for the structure to rest on (steel; $0.140 \times 0.100 \times 0.015 \mathrm{~m} ; 12,768$ elements, 15,561 nodes; hexahedral mesh). Rigid material models (*MAT_RIGID) were assigned to these parts, with the base plate fully constrained and the hammer constrained in all but the y-direction (vertical) to replicate its movement on the rail in the drop tower experiment. Each rigid body had a maximum element size of $2.5 \mathrm{~mm}$.

A contact algorithm was assigned between the lattice and the base plate, as well as between the lattice and the flat impactor (*CONTACT_AUTOMATIC_SURFACE_TO_SURFACE). Different 


\section{WILEY-VCH}

contact algorithms were used for the contact between the hemispherical hammer and the lattice (*CONTACT_AUTOMATIC_NODES_TO_SURFACE; asymmetric), and for the self-contact between the lattice ribs (*CONTACT_AUTOMATIC_SINGLE_SURFACE), as recommended for structural impacts. ${ }^{[90,94]}$ All friction coefficients were set to 0.7 for these contacts, based on a study of tires (using the same TPU) on an aluminum rail. ${ }^{[95]}$ Other LS-DYNA specific settings were included for the rigid body contacts (soft constraint formulation; SOFT=1, soft constraint scale factor, 0.3; viscous damping coefficient, 10; slave penalty scale factor, 1) and for the TPU selfcontact (segment based contact setting, soft $=2$; soft constraint scale factor, 0.3 ; viscous damping coefficient, 50; slave penalty scale factor, 5; solid element thickness, $5 \times 10^{-5} \mathrm{~m}$ ). ${ }^{[90,94]}$ A time-step safety (scale) factor of 0.5 was used with a maximum time step size of $2 \times 10^{-6} \mathrm{~s}$ to prevent negative volume errors. ${ }^{[00,94]}$ After pilot simulations, an hourglass control (Flanagan-Belytschko Stiffness Form; LS-DYNA ID 4) of 0.10 was used, with the default settings of quadratic bulk (1.5) and linear bulk (0.06), to ensure the hourglass energy was less than $10 \%$ of the internal energy of the system for each simulation. $[90,94]$

Initially, a linear elastic material model (*MAT_ELASTIC) was assigned to the lattice, using data from Yang for the same TPU $\left(\rho, 1,200 \mathrm{~kg} / \mathrm{m}^{3} ; E, 15 \mathrm{MPa} ; v, 0.48\right),{ }^{[96]}$ but this resulted in excessive deformation of the structure under impact, indicating insufficient stiffness and the requirement for a more complex material model. Non-linear hyperelastic material models were trialed, including Ogden, Polynomial and Mooney-Rivlin. ${ }^{[90]}$ The Mooney-Rivlin 5 parameter (*MAT_HYPERELASTIC_RUBBER five term, with optional viscoelastic card in the form of a Prony series) ${ }^{[90]}$ was consequently assigned to predict the experimentally measured stress $v s$ strain relationship and determine material coefficients $\left(C_{i j}\right)$ using $A N S Y S^{\circledR}$ Engineering Data. Equation (2) outlines the constitutive model of the Mooney-Rivlin 5 parameter material model, derived from the strain energy function $(W)$ and three strain invariants $I_{1}, I_{2}$ and $I_{3}$, where $C_{i j}$ are material constants relating to the shear behavior. ${ }^{[97]}$ 


\section{WILEY-VCH}

$W_{(5)}=C_{10}\left(I_{1}-3\right)+C_{01}\left(I_{2}-3\right)+C_{20}\left(I_{1}-3\right)^{2}+C_{02}\left(I_{2}-3\right)^{2}+C_{11}\left(I_{1}-3\right)\left(I_{2}-3\right)$

Three sets of stress $v s$ strain relationships were trialed in the hyperelastic material model and tested in the impact simulations, corresponding to: i) the compression test data at the highest strain rate $\left(\sim 19 \mathrm{~s}^{-1} ; E, \sim 20 \mathrm{MPa}\right.$, up to $10 \%$ strain) in isolation, ii) the compression test data at the highest strain rate combined with the tensile test data and iii) data obtained from impact testing the cylindrical compressive samples, as detailed in the following sub-section (2.4). For ii), the experimental stress values from the tensile data at the maximum strain rate $\left(\sim 3 \mathrm{~s}^{-1}\right)$ were artificially stiffened, since the test was at a lower strain rate than the compressive test. The stiffening factor applied to the tensile data was tuned by matching simulation and experimental results, similar to the approach of Smith \& Duris ${ }^{[69]}$ fitting viscoelastic parameters to improve sports ball model and experimental agreement and Andena et al. ${ }^{[98]}$ extrapolating low strain rate experimental data to higher strain rates during sport surface model development.

The shear modulus vs time data from the stress relaxation test was curve-fit to a three term Prony series (Equation (3): $G$, shear modulus; t, time; $\alpha$, shear constant; $\beta$ time constant), as reported by Smith \& Duris when characterizing polyurethane softball cores, ${ }^{[69]}$ to determine six viscoelastic constants: $\alpha_{\mathrm{i}}$ and $\beta_{\mathrm{i}}$ (Mechanical APDL v18.2 (LTSC, CA, USA)).

$G(t)=\sum_{i=1}^{3} \alpha_{i} e^{-\beta_{i} t}$

The hyperelastic and Prony series coefficients, and the value determined for $v$, were used to form a material model specific to the TPU. The $\rho$ from the TPU data sheet was included, ${ }^{[80]}$ with the maximum shear modulus $\left(G_{\max }\right)$, determined from experimental stress relaxation data (with the factor of ten rule applied) (Figure 2), used as the 'frequency independent damping' value. ${ }^{[90]}$ Critical stress (notation: $S I G F$ ) was calculated by dividing $G_{\max }$ by $250 .{ }^{[90]}$ The material model snippet (Table 1) was applied to the TPU bodies for each lattice and simulations were run for impact energies of $1 \mathrm{~J}, 3 \mathrm{~J}$ and $5 \mathrm{~J}$. Simulation results for all lattice impacts were generated via the 


\section{WILEY-VCH}

explicit dynamic solver, LS-DYNA vR8.1.0 (LSTC), with LS-Pre-Post-4.3 (LSTC) used for postprocessing.

\subsection{Impact testing of auxetic structures}

The drop hammer was attached to a carriage (Linear 488-5136, RS Components, Corby, UK) on a slide rail (Linear WS-10-40-1000, 488-5243, RS) and held and released by a magnet-coupling device (F4M905 $70 \mathrm{~kg}$ Pull, First4Magnets, UK). The lattice to be impacted was positioned on an aluminum plate $(0.118 \times 0.118 \times 0.015 \mathrm{~m})$ that was attached to a large steel plate $(0.75 \times 0.45 \times$ $0.04 \mathrm{~m})$ via a uniaxial load cell $(208 \mathrm{C} 05, \mathrm{PCB}, \mathrm{UK})$ close to each corner. This setup created a bespoke force platform, whereby the load cells recorded temporal voltage that was converted to force using their calibration factor (as provided by supplier - mean, $0.230 \mathrm{mV} / \mathrm{N}$; standard deviation, $+0.002 \mathrm{mV} / \mathrm{N})$. The force platform was similar to the design used by Smith et al. for testing sports balls. ${ }^{[99]}$

The load cells were connected to two three-channel signal conditioners (480B21, PCB, UK - x10 gain), which were connected to a digital oscilloscope (PicoScope 4424, PicoTech, UK). Each impact was filmed (resolution, 512:320 pixels; sample rate, $10 \mathrm{kHz}$ ) with the camera used for tensile testing placed approximately $0.2 \mathrm{~m}$ in front of the lattice, which was aligned in the center of the image. The camera was synchronized with the load cells via the oscilloscope (trigger level, 500 $\mathrm{mV}$; sample rate, $10 \mathrm{kHz}$ ), and was activated by a manual trigger as the hammer was released (falling edge, $0.5 \mathrm{~V}$ ). The vertical axis of the lattice was aligned with that of the drop hammer by eye, with the impact position checked in the video footage. Each impact per energy was repeated three times and mean values for peak force, maximum axial strain and impact duration were determined. The camera was calibrated using the measured height of the un-deformed lattice (e.g. re-entrant $=46.5 \mathrm{~mm}$ ) in each video (Phantom Cine Viewer v3.0.770.0), allowing maximum axial deformations to be manually measured and converted to strain (estimated error of within $1 \mathrm{~mm} /$ 


\section{WILEY-VCH}

$\sim 2 \%$ strain). Impact duration was measured experimentally by cross-referencing synchronized video and load cell data to identify the start and end of contact (estimated error of within $0.5 \mathrm{~ms} / 5$ frames). The repeat showing the closest overall agreement with these mean values was used for force $v s$ time plots, the experimental images at maximum axial strain presented in the results section and for the approximation of Poisson's ratio.

To investigate the agreement between the simulation and experiment: peak forces, maximum axial strains, impact durations and Poisson's ratios were compared. Values for Poisson's ratio were determined for the lattices for flat plate impacts at $3 \mathrm{~J}$. A central region for each lattice was selected and two axial $\left(\mathrm{y}_{1}, \mathrm{y}_{2}\right)$ and two lateral displacements $\left(\mathrm{x}_{1}, \mathrm{x}_{2}\right)$ were measured, up to $\sim 0.2$ axial strain (Figure 1). Experimentally, this was done using Phantom Cine Viewer (as detailed previously), with measurements taken every 5 frames $(0.5 \mathrm{~ms})$ and the same reference point for each measurement manually selected. For simulations, specific nodes were selected with $\mathrm{x}$ and $\mathrm{y}$ displacements measured using LS-Pre-Post-4. 3 every $\sim 0.3 \mathrm{~ms}, 0.2 \mathrm{~ms}, 0.25 \mathrm{~ms}$ and $0.5 \mathrm{~ms}$ for the re-entrant, antitetra chiral, hound's-tooth and conventional lattices respectively (different sample rates due to different impact durations). Lateral and axial strains were calculated and plotted using Microsoft Excel, with the gradient of a linear trend line used to approximate Poisson's ratio.

The drop tower rig was also used to impact test the five cylindrical compressive samples, using the flat dropper, to obtain high strain rate stress $v s$ strain data for the TPU. The approach was similar to that of Burbank and Smith who developed an impact test method to obtain stress $v s$ strain data for polyurethane foam at high strain rates for modeling sports balls, ${ }^{[100]}$ and Ankrah and Mills who characterized ethylene vinyl acetate foam for modeling shin pads with a drop tower. ${ }^{[101]}$ Drop heights varied from 5 to $25 \mathrm{~cm}$ in $5 \mathrm{~cm}$ increments (velocity range, 1.0 to $2.2 \mathrm{~m} / \mathrm{s}$; energy range 0.8 to $3.9 \mathrm{~J}$ ), with the load cells sampling at $200 \mathrm{kHz}$. Each impact energy was repeated three times and showed graphical consistency. A second-order polynomial trend line was fitted to the initial section of the acceleration (force) vs time data (based on visual inspection and avoiding any noisy data 


\section{WILEY-VCH}

towards maximum compression), which corresponded to sample loading. Smoothed acceleration $v s$ time data was generated from the equation of the trend line, and the trapezium method was applied to obtain the strain $v s$ time relationship. Stress $v s$ strain relationships were then obtained using the acceleration (force) data generated previously from the equation of the trend line. Maximum displacements/strains were calculated and compared to those measured in the video footage to check accuracy (e.g. stress $v s$ strain data used in FE models at $10 \mathrm{~cm}$ impact height; velocity, 1.4 $\mathrm{m} / \mathrm{s}$; energy, $1.6 \mathrm{~J}$, calculated maximum displacement of $1.98 \mathrm{~mm}$ vs measured maximum displacement of $1.85 \mathrm{~mm}$; strain, $\sim 0.2$ ). Strain rate during sample loading was approximated from the gradient of a linear trend line fitted to strain $v s$ time data, acknowledging that the rate of compression is inherently changing as the drop hammer decelerates.

\section{Results}

\subsection{Material Characterization}

Poisson's ratio of the TPU dog-bone samples decreased in a quasi-linear fashion from $\sim 0.45$ to $\sim 0.25$, as tension increased up to $40 \%$. The maximum $v(\sim 0.45)$ and the corresponding tensile modulus ( $7 \mathrm{MPa}$, up to $10 \%$ strain), were both lower than the values of $v=0.48$ and $E=15 \mathrm{MPa}$ in Yang et al., ${ }^{[96]}$ although this publication did not provide details of material characterization techniques, AM procedures nor printer settings. The compressive modulus obtained from the compressive testing (at $\sim 19 \mathrm{~s}^{-1}$ ) was $\sim 20 \mathrm{MPa}$ (also up to $10 \%$ strain); closer to the published $E$ value of Yang et al.

Compression testing showed the TPU to be rate dependent, increasing in stiffness with strain and strain rate (Figure $2 a$ ). The rate dependency of the TPU was further highlighted in the data from the impact tests on the compressive samples (strain rate range, $\sim 96$ to $\sim 220 \mathrm{~s}^{-1}$ ) (Figure 2a), where the stiffness was almost twice that of the compression tests (E range, $\sim 32$ to $36 \mathrm{MPa}$, up to $10 \%$ strain). When using the compression test data in isolation to obtain the Mooney-Rivlin coefficients, the simulation over-predicted the deformation of the lattice in comparison to the experiment. When 


\section{WILEY-VCH}

using the combined compression and tensile data in the material model, broad agreement was obtained between the simulated and experimental impacts on the lattices. The tensile data had to be stiffened by a factor of six, however, which was considered excessive. The stress $v s$ strain data obtained from the impact test on the compressive samples obtained at a drop height of $10 \mathrm{~cm}$ (strain rate, $\sim 140 \mathrm{~s}^{-1}$; E, $\sim 32 \mathrm{MPa}$ ) was, therefore, used to obtain the Mooney-Rivlin coefficients, as this provided broad agreement with the experimental impact data on the lattices, without any tuning required.

The six Prony series coefficients for an applied strain of 0.4 in the stress relaxation test (and $v=$ 0.45) were selected due to the marginally higher strain rate achieved during loading, although a sensitivity analysis indicated that using the coefficients for either strain made no clear difference to simulation outputs (Figure $2 b$ ).

\subsection{Impact testing (experimental and simulations)}

Figure 3 shows experimental force $v s$ time plots (EXP) for 1.0 ('low'), 3.0 ('medium') and $5.0 \mathrm{~J}$ ('high') impacts, with equivalent simulation (SIM) plots overlaid for comparison, for each lattice and hammer type. FE model and experimental images at maximum deformation at the impact energy of $3 \mathrm{~J}$ are included for visual inspection and comparison (Figure 4). Table 2 displays the maximum discrepancies between experimental and FE results for all lattices, and complete results are included in 'Supporting Information'. In general, the trends reported were observed both experimentally and within the simulation results.

For all lattices, and both flat and hemispherical impacts, peak force and maximum axial strain increased with impact energy (Figure 3). The impact duration increased with impact energy for antitetra chiral_flat (Figure 3c), but decreased with increasing impact energy for the other lattices (Figure 3d, $\mathrm{f}$ and $\mathrm{h}$ ).

When comparing results for the two drop hammers at equivalent energies, the hemisphere exhibited lower peak forces (except for re-entrant and anti-tetra chiral at $5 \mathrm{~J}$ and for the 


\section{WILEY-VCH}

conventional honeycomb at 3 and $5 \mathrm{~J}$ ), longer impact durations (Figure 3) and increased axial strain (Figure 4).

When comparing the auxetic lattice designs across all impact energies, the re-entrant exhibited the lowest stiffness in compression (also lowest mass/volume). The re-entrant lattice also recorded the lowest mean peak force ( $310 \mathrm{~N}$ for flat and $304 \mathrm{~N}$ for hemisphere), the longest mean impact duration (28.5 $\mathrm{ms}$ for flat and $42.3 \mathrm{~ms}$ for hemisphere), and the largest mean axial strain (0.3 for flat and 0.4 for hemisphere). The anti-tetra chiral lattice recorded the highest mean peak forces $(659 \mathrm{~N}$ for flat, $550 \mathrm{~N}$ for hemisphere), the lowest mean axial strain ( 0.1 for flat) and had the shortest mean impact duration ( $12.0 \mathrm{~ms}$ for flat and $21.0 \mathrm{~ms}$ for hemisphere), indicating it was the lattice with the highest stiffness in compression.

When comparing all lattices, the conventional honeycomb exhibited the lowest mean peak force under flat hammer impacts $(279 \mathrm{~N})$, although the peak force recorded for the impact at $5 \mathrm{~J}$ was 100 $\mathrm{N}$ higher than the re-entrant lattice equivalent. The highest peak force overall was for the conventional honeycomb lattice at the hemispherical impact of $5 \mathrm{~J}(1,009 \mathrm{~N})$. The mean impact duration and mean axial strain for the conventional honeycomb lattice were both greater than for the auxetic lattices, for both flat and hemisphere impacts.

The FE models agreed with the trends detailed previously and showed broad agreement with experimental results, as shown in Figure 4 (and supported by the general shape of the force vs time plots in Figure 3). All auxetic lattices showed an NPR in both experimental and simulation analysis, confirming that they were auxetic, while the conventional honeycomb lattice exhibited a positive Poisson's ratio, as expected, with simulation and experimental results matching at 0.36 (Figure 5). For the auxetic lattices, the re-entrant exhibited the greatest magnitude of NPR $(-0.81$ experimentally $v s-1.08$ in simulations), despite having the worst agreement between model and experiment, whilst the hound's-tooth displayed the lowest magnitude of NPR and best agreement (- 


\section{WILEY-VCH}

0.46 experimental $v s-0.44$ simulation). The anti-tetra chiral showed fair agreement (-0.68 experimental $v s-0.86$ simulation) (see Supporting Information).

\section{Discussion}

The FE models of three auxetic lattices and a conventional honeycomb lattice under impact showed broad agreement with experimental data, when comparing force $v$ s time plots (Figure 3) and images at maximum compression (Figure 4). The modeling techniques have been validated across three established auxetic lattices and a conventional honeycomb equivalent, ${ }^{[89,91-93]}$ two hammer shapes and a range of impact energies $(1 \mathrm{~J}$ to $5 \mathrm{~J}$ ). Agreement with the experiments across this range of scenarios demonstrates the robustness of the FE models and their suitability in predicting the performance of different lattice shapes and designs, particularly as there will be inherent variation in the AM of test samples. The four lattice designs exhibited clear differences in behavior under impact, further highlighting the potential of using FE modeling techniques for tailoring mechanical properties for a particular sporting application. The potential of auxetics in a sporting context has been demonstrated previously, and further highlighted in this study through FE models validated against AM prototypes, which can now be applied to develop auxetic sporting PPE products. ${ }^{[6,7,10,25]}$

In particular, the effect of scaling lattice size and shape to be representative of specific sporting PPE products, such as body padding or helmet liners, could now be investigated. In parallel, the effect of auxetic unit-cell parameters on the impact performance of the lattice, ${ }^{[52]}$ using established or new designs, can be explored in relation to injury specific criterion. Higher impact energies should also be considered, such as those seen in Foster et al., ${ }^{[26]}$ where energies up to $\sim 40 \mathrm{~J}$ were used to test a helmet featuring auxetic foam.

The strain rate used to obtain the compression data for the TPU was the maximum possible with the available Instron machine $\left(\sim 19 \mathrm{~s}^{-1}\right)$ and the sample size tested. The maximum achievable strain rate for stress relaxation data was lower at $\sim 12 \mathrm{~s}^{-1}$ due to the nature of the experiment (one 


\section{WILEY-VCH}

compressive cycle). In tension, the maximum strain rate (without excessive noise) was $\sim 3 \mathrm{~s}^{-1}$ and the stress $v s$ strain data from these tests had to be artificially stiffened to provide Mooney-Rivlin material model coefficients that gave acceptable, but subjective, agreement between simulation and experimental results. Impact testing compressive samples, similar to the work of Burbank and Smith and Ankrah and Mills, ${ }^{[100,101]}$ produced Mooney-Rivlin coefficients that resulted in broad agreement between the simulation and experiment for the auxetic lattices. While these coefficients will allow the FE model to be used as a design tool, there are limitations associated with this material testing approâch, such as the level of measurement accuracy, the achievable range and consistency in strain rate during loading and the lack of tensile data. Future work should therefore investigate more established methods of characterizing the TPU (and other potential candidate materials) at these higher strain rates that are more representative of those experienced by the material in the lattice under impact. For example, using a split Hopkinson bar or dynamic mechanical analysis, as used by Signetti et $a l$. to characterize closed cell polymeric foams for modeling back protectors. ${ }^{[12,102]}$ DIC, alongside the FE models, could also be used to obtain the strains and strain rates present in auxetic lattices under impact to give representative values to help inform material testing strategies, similar to the work of Lane et al. for sports balls. ${ }^{[85]}$

The specific AM settings (e.g. nozzle diameter or layer height), combined with the printer used and its condition, can affect the properties of the TPU and dimensional accuracy of the lattices. Pilot testing also indicated some variation between colors of TPU and between spools of the same color. Therefore, care should be taken when transferring the results presented within this study for material and impact testing to other applications, and further work should look to assess inherent variation in $\mathrm{AM}$ and the influence of this on the experimental results and predictions of the models.

When compared to experimental results, the FE models for all lattices under predicted peak forces at $1 \mathrm{~J}$ but over-predicted peak forces for $3 \mathrm{~J}$ and $5 \mathrm{~J}$. There were exceptions for hound'stooth_hemisphere and conventional honeycomb_hemisphere at $3 \mathrm{~J}$, which under-predicted peak 


\section{WILEY-VCH}

force. In the simulations, the vertical axis of the drop hammer was aligned with that of the lattice but there was likely to be some variation in impact location during experimental testing, although this was not measured specifically. Additional simulations with the hemispherical drop hammer offset from the center of the lattice by $2.5 \mathrm{~mm}$ resulted in a marginal reduction in peak impact force and an increase in contact duration (e.g. $<5 \%$ for anti-tetra chiral), which may explain some of the discrepancy between the model and experiment results.

For re-entrant_hemisphere, both the experimental video footage and simulation animations showed the lattice to buckle sideways in a similar manner (Figure 4), although the simulations appeared to over-exaggerate this movement. The relative size of the hemisphere compared to the lattices was large and these edge effects may be less prevalent once the lattices are scaled to sizes more representative of sporting PPE. The issue was not seen with anti-tetra chiral_hemisphere, as the anti-tetra chiral lattice has a more continuous boundary (Figure 4), and this could be a consideration when selecting and developing candidate auxetic lattices for further testing in sporting PPE applications. Future work should look to quantify the performance of each lattice, based on key parameters relevant to sporting PPE, such as force limitation and energy absorption.

The conventional honeycomb lattice exhibited lower peak forces and longer impact durations than the auxetic lattices at $1 \mathrm{~J}$ and $3 \mathrm{~J}$ (for flat and hemisphere impacts), indicating better impact performance at these impact energies. For $5 \mathrm{~J}$ impacts on the conventional honeycomb lattice, however, the peak force recorded for the hemisphere was the largest of all lattices, and the flat impact was larger than the re-entrant lattice. The auxetic lattices can be seen to contract laterally and densify beneath the drop hammer (Figure 3), preventing them from "bottoming out", as is the case for the conventional honeycomb lattice at $5 \mathrm{~J}$ (particularly with the hemisphere), which expanded laterally and exhibited high axial compression ( $75 \%$ for hemisphere) and a 'spike' in impact force. These results indicate that auxetic lattices are more resistant to "bottoming out" than

their conventional counterparts, ${ }^{[24,25]}$ providing further evidence that auxetic materials may be well 


\section{WILEY-VCH}

suited for application in sporting PPE intended to offer protection across as range of impact scenarios.

The Poisson's ratios presented in this paper were approximated at $3 \mathrm{~J}$ for each lattice, which was sufficient to confirm their auxetic nature during high strain compression. The Poisson's ratio measured experimentally $(-0.81)$ for the re-entrant lattice had a smaller magnitude than values reported in the literature, which approach -1 with an equivalent cell angle of $-30^{\circ}$, based on the cellular material theory from Gibson and Ashby, ${ }^{[84]}$. The simulation value was -1.08 , and substituting the re-entrant dimensions from Figure 1a into this theory, a greater magnitude of Poisson's ratio was predicted (-1.22). Isotropic chiral auxetic structures have a theoretical Poisson's ratio of $-1,{ }^{[45]}$ although this is dependent on the chiral-type and the thickness of the cell ribs. ${ }^{[55]}$ The difference in NPR for the experimental (-0.68) and simulation values (-0.86) of the anti-tetra chiral, when compared to this theoretical study, could thus be explained by the different unit-cell wall thickness used in this study. The hound's-tooth showed good agreement for Poisson's ratio (0.44 simulation $v-0.46$ experimental), although values obtained were lower than those reported by Smith et al. ( -0.6). ${ }^{[92]}$ Future work could investigate Poisson's ratio in more detail, considering factors such as how it changes with applied strain and strain rate, which could be facilitated experimentally by using automated tracking software. The effect of the unit-cell design, including increasing the concentration of unit-cells within each lattice, could be amended so their behavior is more representative of a continuum material.

The validated material model could be extended to other auxetic structures, including new designs, a combination of structures or be developed further to improve simulation and experimental agreement. The material characterization process could be used to investigate other materials within the FE model, which also have potential to progress the use of auxetic materials in sporting PPE. The auxetic lattices investigated here were limited to $2.5 \mathrm{D}$ and future work could use the model to explore 3D structures, with support material used in the AM of any prototypes. ${ }^{[70,76]}$ 


\section{WILEY-VCH}

Investigating multi-material auxetic structures could also be of particular interest. ${ }^{[76]}$ The work presented here is limited to linear impacts, and future work could investigate auxetic structures under oblique impacts, which are of particular relevance to sports helmets, where limiting rotational acceleration is an important consideration. ${ }^{[26,49]}$

\section{Conclusion}

FE models for TPU lattices have been developed and validated, across two impact scenarios (flat and hemispherical) and a range of energies ( $1 \mathrm{~J}$ to $5 \mathrm{~J})$, with a broad agreement being shown for four designs: re-entrant, anti-tetra chiral, hound's-tooth and conventional honeycomb. The benefit of combining FE modeling and AM when investigating auxetic and conventional honeycomb lattices under impact has been demonstrated, laying the foundations for future work in this area concerning sporting PPE. Validating the impact response of three auxetic lattices and a conventional honeycomb lattice with two drop hammer types, including a concentrated load that commonly occurs in sporting impacts, has not been reported as a systematic process before. The validated FE models can consequently be used to expand on this initial study and develop auxetic products that are particularly relevant to application within sporting PPE. Exploratory design studies for specific sporting PPE products of varying complexity can consequently be undertaken with the FE models, without having to continuously manufacture physical prototypes and subject them to repeated experimental work.

\section{Supporting Information}

Supporting Information is available from the Wiley Online Library or from the author.

\section{Acknowledgements}

The authors would like to thank Mike Green for his technical support and patience during mechanical testing. Also thanks to Haydn Insley for his assistance and advice with AM and using the Lulzbot ${ }^{\circledR}$ Taz 5 AM machine and flexible filaments. They would also like to thank colleagues who provided assistance in proofreading and finalizing the submission, including Dr. Olly Duncan and Dr Chloe Newton-Mann. 


\section{WILEY-VCH}

Received: ((will be filled in by the editorial staff))

Revised: ((will be filled in by the editorial staff))

Published online: ((will be filled in by the editorial staff))

\section{References}

[1] S.P. Timoshenko, J.M. Gere, Theory of elastic stability. Courier Corporation, MA, USA 2009.

[2] K.W. Wojciechowski, J. Phys. Soc. Jpn. 2003, 72, 1819.

[3] R.S. Lakes, Science 1987, 235, 1038.

[4] N. Chan, K.E. Evans, J. Cell. Plast. 1998, 34, 231.

[5] R.S. Lakes, K. Elms, J. Comp. Mater. 1993, 27, 1193.

[6] M. Sanami, N. Ravirala, K. Alderson, A. Alderson, Procedia Eng. 2014, 72, 453.

[7] O. Duncan, T. Shepherd, C. Moroney, L. Foster, P. Venkatraman, K. Winwood, T.Allen, A. Alderson, Appl. Sci. 2018, 8, 941.

[8] C. Moroney, A. Alderson, T. Allen, M. Sanami, P. Venkatraman, in Proc. 12th Conference of the International Sports Engineering Association (Eds: H.G. Espinosa, D. R. Rowlands, J.

Shepherd, D.V. Thiel), Brisbane, Australia, 2018, 2.

[9] J.M. Johnston, H. Ning, J.E. Kim, Y.H. Kim, B. Soni, R. Reynolds, L. Cooper, J.B. Andrews, U. Vaidya, Sports Eng. 2015 18, 11.

[10] a) T. Allen, O. Duncan, L. Foster, T. Senior, D. Zampieri, V. Edeh, A. Alderson, in Proc. International Society for Skiing Safety (Eds: I.S. Scher, R.M. Greenwald, N. Petrone), Cham, Switzerland, 2017, 21; b) F. I. Michel, K. U. Schmitt, R. M. Greenwald, K. Russell, F. I. Simpson, D. Schulz, M. Langran, Sports Eng. 2013, 16, 197.

[11] A. S. McIntosh, T. E. Andersen, R. Bahr, R. Greenwald, S. Kleiven, M. Turner, M. Varese, P. McCrory, Br. J. Sports Med. 2011, 45, 1258. 


\section{WILEY-VCH}

[12] a) T.J. Dickson, S. Trathen, F.A. Terwiel, G. Waddington, R. Adams, Scand. J. Med. Sci.

Sports 2017, 27, 236; b) A. Ekeland, A. Rødven, S. Heir, in Proc. International Society for Skiing

Safety (Eds: I.S. Scher, R.M. Greenwald, N. Petrone), Cham, Switzerland, 2017, 21.

[13] S. Signetti, M. Nicotra, M. Colonna, N.M. Pugno, J. Sci. Med. Sport, https://doi.org/10.1016/j.jsams.2018.10.007.

[14] E. Petridou, S. Kedikoglou, M. Belechri, F. Papadopoulos, D.M. Alexe, D. Trichopoulos, Eur. J. Trauma 2003, 29, 278 .

[15] R. Kisser, R. Bauer, Austrian Road Safety Board, ISBN 978-3-7070-0108-2, 2012.

[16] N. Priest, R. Armstrong, J. Doyle, E. Waters, Cochrane Database Syst. Rev. https://doi.org/10.1002/14651858.CD004812.pub3

[17] British Heart Foundation National Centre (BHFNC), 2014, 'Economic Costs of Physical Inactivity'. Available online at http://www.ssehsactive.org.uk. (Accessed March 19, 2019).

[18] R.M. Eime, J.A. Young, J.T. Harvey, M.J. Charity, W.R. Payne, Int. J. Behav. Nutr. Phys. Act. 2013, 10,98 .

[19] N. Bailly, J.D. Laporte, S. Afquir, C. Masson, T. Donnadieu, J.B. Delay, P.J. Arnoux, Wilderness Environ. Med. 2018, 29, 151.

[20] B. D. Wilson, Sports Med. 1998, 25, 333.

[21] F. Barthelat, H. Tang, P.D. Zavattieri, C.M. Li, H.D. J. Espinosa, Mech. Phys. Solids 2007, 55, 306.

[22] a) N. Chan, K.E. Evans, 1997, 32, 5725; b) N. Chan, K.E. Evans, J. Mater. Sci. 1997, 32, 5945.

[23] F. Scarpa, J.R. Yates, L.G. Ciffo, S. Patsias, Proc. Inst. Mech. Eng, Part C 2002, 216, 1153.

[24] a) T. Allen, N. Martinello, D. Zampieri, T. Hewage, T. Senior, L. Foster, A. Alderson, Procedia Eng. 2015, 112, 104; b) T. Allen, J. Shepherd, T. Hewage, T. Senior, L. Foster, A. Alderson, Phys. Status Solidi B 2015, 9, 1631.

This article is protected by copyright. All rights reserved 


\section{WILEY-VCH}

[25] O. Duncan, L. Foster, T. Senior, A. Alderson, T, Allen, Smart Mater. Struct. 2016, 25, 54014.

[26] L. Foster, P. Peketi, T. Allen, T. Senior, O. Duncan, A. Alderson, Appl. Sci. 2018, 8, 354.

[27] C.W. Gadd, 1966 (No. 660793). SAE Technical Paper. https://doi.org/10.4271/660793.

[28] O. Duncan, L. Foster, T. Senior, T. Allen, A. Alderson, Procedia Eng. 2016, 147, 384.

[29] M.A. Loureiro, R.S. Lakes Cell. Polym. 1997, 16, 349.

[30] M. Bianchi, F. Scarpa, M. Banse, C.W. Smith, Acta Mater. 2011, 59, 686.

[31] A. Bezazi, F. Scarpa, Int. J. Fatigue, 2007, 29, 922. b) A. Bezazi, F. Scarpa, Int. J. Fatigue

2009, 31,488 .

[32] O. Duncan, T. Allen, L. Foster, T. Senior, A. Alderson, Acta Mater. 2017, 126, 426.

[33] T. Allen, T. Hewage, C. Newton-Mann, W. Wang, O. Duncan, A. Alderson, Phys. Status Solidi B 2017, 254, 1700596.

[34] a) Y. Li, C. Zeng, Adv. Mater. 2016, 28, 2822; b) Auxadyne. XPF auxetic foam technology [Internet]. Web Page. 2019. Available online: https://www.auxadyne.com/home.html (accessed on March 19, 2019)

[35] O. Duncan, T. Allen, L. Foster, R. Gatt, J.N. Grima, A. Alderson, in Proc. 12th Conference of the International Sports Engineering Association (Eds: H.G. Espinosa, D. R. Rowlands, J. Shepherd, D.V. Thiel), Brisbane, Australia, 2018, 2.

[36] O. Duncan, F. Clegg, A. Essa, A.M. Bell, L. Foster, T. Allen, A. Alderson, Phys. Status Solidi B 2019, 1800393.

[37] D. Fan, M. Li, J. Qiu, H. Xing, Z. Jiang, T. Tang, ACS Appl. Mater. Interfaces 2018, 10, 22669.

[38] D. Skertchly (Global Composites Group), US 20110214560A1, 2011.

[39] a) T.M. Cross, K.W. Hoffer, D.P. Jones, P.B. Kirschner, J.C. Meschter (Nike Inc.), US 20150075034A1, 2015; b) A. Toronjo (UnderArmour Inc.), US 20140059734A1, 2014. 


\section{WILEY-VCH}

[40] D3O. Trust Stealth Helmet Pad System [Internet]. Web Page. 2019. Available online:

https://www.d3o.com/products/trust-stealth-helmet-pad-system/ (accessed on March 19, 2019).

[41] E. Bliven, A. Rouhier, S. Tsai, R. Willinger, N. Bourdet, C. Deck, S.M. Madey, M. Bottlang, Accid. Anal. Prev. 2019, 124, 58.

[42] a) U.D. Larsen, O. Sigmund, S. Bouwsta, J. Microelectromech. Sys. 1997, 6, 99; b) Y. Wang,

L. Wang, Z.D. Ma, T. Wang, Sci. Mater. Struct. 2016, 25, 035038.

[43] L.J. Gibson, M.F. Ashby, Proc R. Soc. London Ser. A Math. Phys. Sci. 1982, 382, 25; [44] R.F. Almgren, $J$. Thermoelasticity 1985, 15, 427;

[45] D. Prall, R.S. Lakes. Int. J. Mech. Sci. 1997, 39, 305.

[46] a) J.N. Grima and K.E Evans, J. Mater. Sci Lett, 2000, 19, 1563; b) J. N. Grima, A. Alderson, and K.E. Evans, Phys. Status Solidi B 2005, 242, 561; c) J.N. Grima, V. Zammit, R. Gatt, A. Alderson and K.E. Evans, Phys. Status Solidi B 2007, 244, 866.; d) D. Attard, J.N. Grima. Phys. Status Solidi B 2012, 249, 1330; e) J.N. Grima, R. Gatt, N. Ravirala, A. Alderson, K.E. Evans, Mater. Sci. Eng., A 2006, 423, 214.

[47] a) K. W. Wojciechowski, Mol. Phys, 1987, 61, 1247; b) K. W. Wojciechowski, Phys. Lett. A, 1989, 137,60 .

[48] C. Newton-Mann, K. Winwood, H. Driscoll, N.Hamilton, T. Allen, in Proc. 12th Conference of the International Sports Engineering Association (Eds: H.G. Espinosa, D. R. Rowlands, J. Shepherd, D.V. Thiel), Brisbane, Australia, 2018, 2.

[49] a) C. Deck, R. Willinger, D. Baumgartner, WIT Trans. Built Environ. 2003, 67; b) Y. Mosleh, M. Cajka, B. Depreitere, J. Vander Sloten, J. Ivens, Proc. Inst. Mech. Eng., Part H 2018, 232, 479. [50] a) T. Allen, S.Haake, S. Goodwill, Sports Eng. 2009, 12, 87; b) B.T. Kays, L.V. Smith, Sports Eng. 2016, 20, 245; c) P. Valentini, E. Pennestrì, L. Quattrociocchi, Sports Eng. 2016 19, 47.

[51] a) D. Cole, S. Forrester, P. Fleming, Appl. Sci. 2018, 8, 501; b) L. Andena, S. Aleo, F. Caimmi, F. Briatico-Vangosa, S. Mariani, S. Tagliabue, A. Pavan, Sports Eng. 2018, 21, 453. 


\section{WILEY-VCH}

[52] a) J.P.M. Whitty, F. Nazare, A. Alderson, Cell. Polym. 2002, 21, 69; b) R. Gatt, D. Attard, P.S. Farrugia, K.M. Azzopardi, L. Mizzi, J.P. Brincat, J.N. Grima, Phys. Status Solidi B 2013, 250, 2012; c) F. Scarpa, P. Panayiotou, G. Tomlinson, J. Strain Anal. Eng. Des. 2000, 35, 383.

[53] T. Strek, B.T. Maruszewski, J.W. Narojczyk, K.W. Wojciechowski, J. Non-Cryst. Solids 2008, $354,4475$.

[54] a) T. Strek, H. Jopek, Phys. Status Solidi B 2012, 249, 1359; b) T. Strek, H. Jopek, B.T.

Maruszewski, M. Nienartowicz, Phys. Status Solidi B 2013, 251, 354; c) A.A. Pozniak, K.W.

Wojciechowski, J.N. Grima, L. Mizzi, Composites, Part B 2016, 94, 379.

[55] a) A.A. Pozniak, K.W. Wojciechowski, Phys. Status Solidi B 2014, 251, 367; b) L. Mizzi, D.

Attard, R. Gatt, A.A. Pozniak, K.W. Wojciechowski, J.N. Grima, Composites, Part B 2015, 80, 84.

[56] a) D.T. Ho, C.T. Nguyen, S.Y. Kwon, S.Y. Kim, Phys. Status Solidi B 2019, 256, 1800122; b)

J.W. Narojczyk, K. W. Wojciechowski, K.V. Tretiakov,

J. Smardzewski, F.Scarpa, P. M. Piglowski, M. Kowalik, A.R. Imre, M. Bilski, Phys. Status Solidi $B, \mathbf{2 0 1 9}, 256,1800611$.

[57] a) W. Liu, N. Wang, T. Luo, Z. Lin, Mater. Des. 2016, 100, 84; b) C. Qi, S. Yang, D. Wang, L.J. Yang, Sci. World J. 2013; c) S. Yang, C. Qi, D. Guo, D. Wang, Appl. Mech. Mater. 2011, 148, 992.

[58] a) Y. Wang, L. Wang, Z.D. Ma, T. Wang, Mater. Des. 2016, 103, 90; b) Y. Wang, Z.D. Ma, L. Wang, Proc. Instit. Mech. Eng., Part D 2016, 230, 983; c) Y. Wang, L. Wang, Z.D. Ma, T. Wang, Proc. Instit. Mech. Eng., Part C 2017, 231, 4374.

[59] W. Wu, X. Song, J. Liang, R. Xia, G. Qian, D. Fang, Compos. Struct. 2018, 185, 381.

[60] F. Scarpa, J. Giacomin, Y. Zhang, P. Pastorino, Cell. Polym. 2005, 24, 253.

[61] Y. Ma, F. Scarpa, D. Zhang, B. Zhu, L. Chen, J. Hong. Smart Mater. Struct. 2013, 22, 084012.

[62] A. Slann, W. White, F.Scarpa, K. Boba, I. Farrow, Phys. Status Solidi B 2015, 252, 1533.

[63] N.J. Mills, A. Gilchrist, WIT Trans. Built Environ. 2003, 67, 319

This article is protected by copyright. All rights reserved 


\section{WILEY-VCH}

[64] D.H. Glaister, Injury, 1986, 17, 376.

[65] F.M. Shuaeib, A.M.S. Hamouda, S.V. Wong, R.R. Umar, M.M. Ahmed, Mater. Des. 2007, 28, 182.

[66] V. Tinard, C. Deck, R. Willinger, Mater. Des. 2012, 37, 79.

[67] a) M.F. Rueda, L. Cui, M.D. Gilchrist, Mater. Des. 2009, 30, 3405; b) L. Cui, M.F. Rueda, M.D. Gilchrist, Mater. Des. 2009, 30, 3414.

[68] F.A. Fernandes, R.J. Alves de Sousa, M. Ptak, G. Migueis, App. Sci. 2019, 9, 735.

[69] L.V. Smith, J.G. Duris, J. Sports Sci. 2009, 27, 353.

[70] a) H.M.A. Kolken, A.A Zadpoor, $R S C A d v .2017,7,5111$; b) X. Ren, J. Shen, P. Tran, T.D. Ngo, Y.M, Xie, Mater. Des. 2018, 139, 336.

[71] A. Cazón-Martín, M. Iturrizaga-Campelo, L. Matey-Muñoz, M.I. Rodríguez-Ferradas, P. Morer-Camo, S. Ausejo-Muñoz, Proc. Inst. Mech. Eng., Part P 2018, 233, 160.

[72] S.P. Soe, P. Martin, M. Jones, M. Robinson, P. Theobald, Int. J. Adv. Manuf. Tech. 2015, 79, 1975.

[73] a) C.K. Chua, K.F. Leong, 3D Printing and Additive Manufacturing: Principles and Applications of Rapid Prototyping (Fourth Edition), World Scientific Publishing Company, Singapore, 2014; b) Materialise, "Adidas futurecraft: the ultimate 3D-printed personalized shoe" [Internet]. Web Page. 2017. Available online: https://www. materialise.com/en/cases/adidasfuturecraft-ultimate-3d-printed-personalized-shoe (accessed March 20, 2019).

[74] a) H.H. Huang, B.L. Wong, Y.C. Chou, Phys. Status Solidi B 2016, 253, 1557; b) N.

Grimmelsmann, H. Meissner, A. Ehrmann, IOP Conf. Ser.: Mater. Sci. Eng. 2016, 137, 012011. [75] a) L. Yang, O.Harrysson, H. West, D. Cormier, J. Mater. Sci. 2013, 48, 1413; b) L. Yang, O.Harrysson, H. West, D. Cormier, Int. J. Solids Struct. 2015, 69, 475; c) D. Li, J. Ma, L. Dong, R.S. Lakes, Mater. Lett. 2017, 188, 149.

[76] K. Wang, Y.H. Chang, Y. Chen, C. Zhang, B. Wang, Mater. Des. 2015, 67, 159. 


\section{WILEY-VCH}

[77] T.D. Ngo, A. Kashani, G. Imbalzano, K.T. Nguyen, D. Hui, Composites, Part B 2018, 143, 172.

[78] European Committee for Standardization. EN 14120:2003, Brussels, Belgium, 2003.

[79] British Standards Institution. BS 6183-1:1981, London, UK, 1981.

[80] NinjaTek Technical specifications, NinjaFlex ${ }^{\circledR}$ 3D Printing Filament, Flexible Polyurethane Material for FDM Printers [Internet] available online: http://dzmlsvv5f118.cloudfront.net/wpcontent/uploads/2016/12/NinjaFlex-TDS-2016.pdf?x89482 (accessed March 20, 2019).

[81] International Organisation for Standardisation. ISO 37:2011, Geneva, Switzerland, 2011.

[82] British Standards Institution. BSEN ISO 386-1:1997, London, UK, 1997.

[83] W. Wang, W., J.E. Mottershead, T. Siebert, A. Pipino, Mech. Syst. Signal Process. 2012, 28, 333.

[84] R. Blenkinsopp, A. Harland, D. Price, T. Lucas, J. Roberts, Procedia Eng. 2012, 34, 266.

[85] B. Lane, P. Sherratt, X. Hu, A. Harland, Appl. Sci. 2018, 8, 371.

[86] a) L. Mullins, Rubber Chem. Technol. 1969, 42, 339; b) J. Diani, B. Fayolle, P. Gilormini, Eur. Polym. J. 2009, 45, 601.

[87] D. Ranga, M. Strangwood, Procedia Eng. 2010, 2, 3287.

[88] J. Sorvari, M. Malinen, Mech. Time-Depend. Mater. 2006, 10, 125.

[89] L.J. Gibson, M.F. Ashby, Cellular Solids: Structure and Properties, Pergamon Press, London, UK 1988.

[90] a) LSTC. LS-DYNA Keyword User's Manual Volume I. Version R10.0 (r:9023). Livermore Software Technology Corporation (LSTC): Livermore, CA, USA, 2017; b) LSTC. LS-DYNA Keyword User's Manual Volume II - Material Models. Version R10.0 (r:9024). Livermore Software Technology Corporation (LSTC): Livermore, CA, USA, 2017; c) LSTC. LS-DYNA Theory Manual. Livermore Software Technology Corporation (LSTC): Livermore, CA, USA, 2017.

This article is protected by copyright. All rights reserved 


\section{WILEY-VCH}

[91] O. Sigmund, S. Torquato, I.A. Aksay, J. Mater. Res. 1998, 13, 1038.

[92] C.W. Smith, J.N. Grima, K.E. Evans, Acta Mater. 2000, 48, 4349.

[93] J.N. Grima, D. Attard, R. Caruana-Gaucib, R. Gatt, Scr. Mater. 2011, 65, 565.

[94] a) Dynasupport.com [Internet]. Web Page. 2019. Available online:

https://www.dynasupport.com (accessed March 20, 2019); b) Sharcnet.ca [Internet]. Web Page.

2019. Available online: https:// www.sharcnet.ca (accessed March 20, 2019).

[95] J.M.G. Farstad, Ø. Netland, T. Welo, in Proc. 27th CIRP Design Conference (Eds: E. Shehab,

T. Tomiyama, H. Lockett, K. Salonitis, R. Roy, A. Tiwari), Cranfield, UK, 2017, 60.

[96] a) C. Yang, H.D. Vora, Y.B. Chang, in Proc. ASME 2016 Conference on Smart Materials,

Adaptive Structures \& Intelligent Systems, VT, USA, 2016, 1. b) C. Yang, H.D. Vora, Y.B. Chang, Smart Mater. Struct. 2018, 27, 25012.

[97] M. Sasso, G. Palmieri, G. Chiappini, D. Amodio, Polym. Test. 2008, 27, 995.

[98] L. Andena, F. Briatico-Vangosa, E. Cazzoni, A. Ciancio, S. Mariani, A. Pavan, Sports Eng.

2015, 18,1 .

[99] L.V. Smith, A.M. Nathan, J.G. Duris, Sports Eng. 2010, 12, 163.

[100] S.D. Burbank, L.V. Smith, Proc. Instit. Mech. Eng., Part P 2012, 226, 77.

[101] S. Ankrah, N.J. Mills, Sports Eng. 2003, 6, 207.

[102] A. Bryson, L. Smith, Procedia Eng. 2010, 2, 2961.

This article is protected by copyright. All rights reserved 


\section{WILEY-VCH}

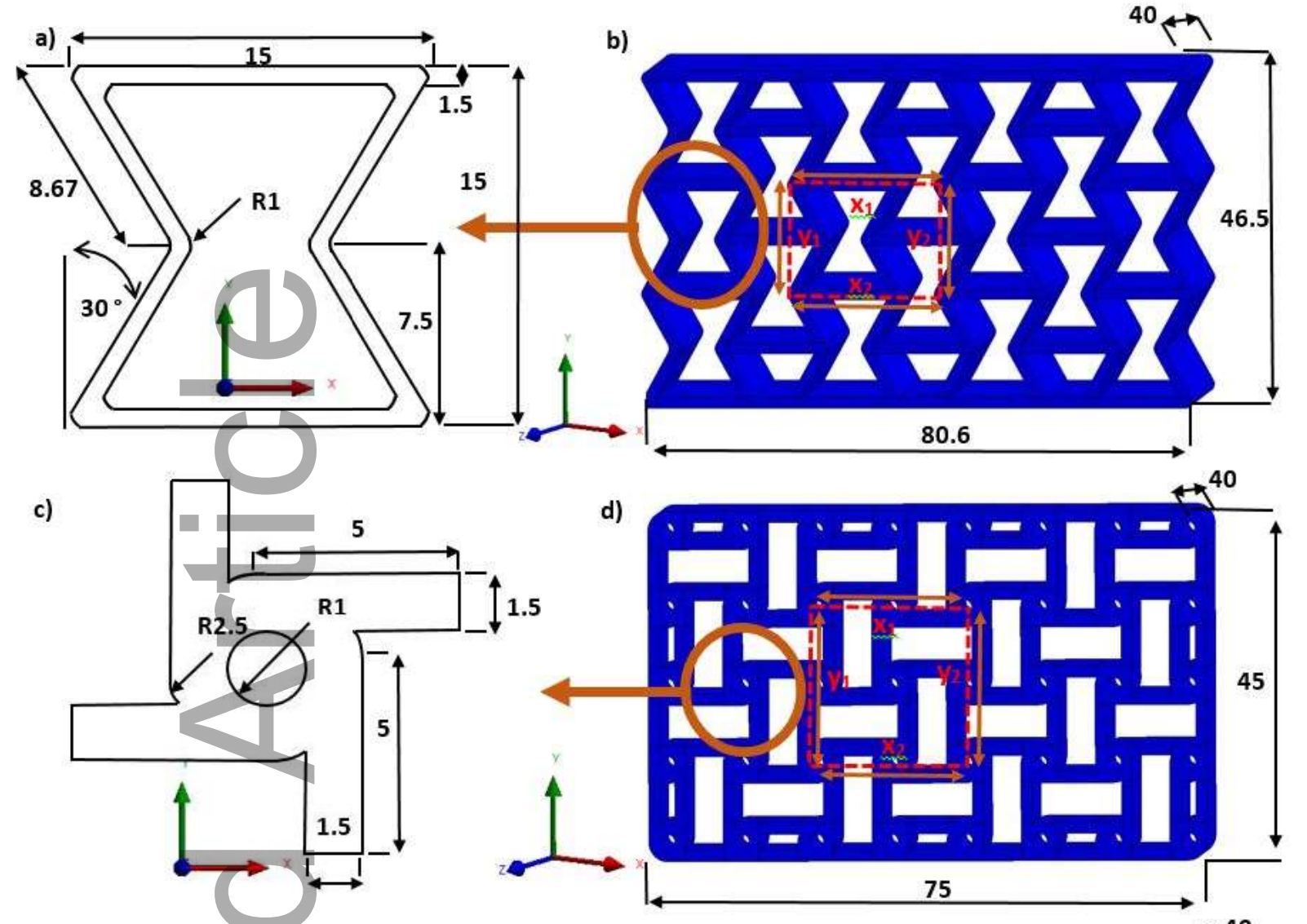

Fig

ure 1.

a)

2D

ske

tch

of

re-

entr

ant

unit
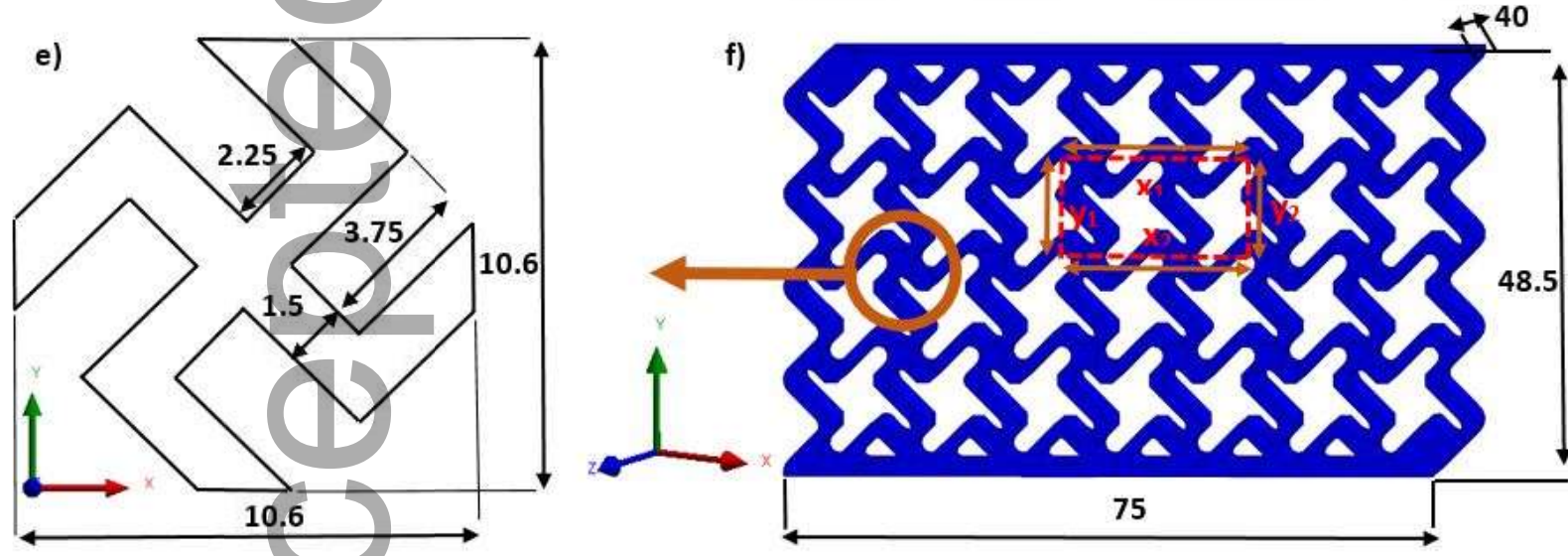

cell

, b)

iso

met

ric

vie

W

of

co

mpl

ete

re-

entr

ant

latti

ce,

c)

2D

ske

tch

of

anti

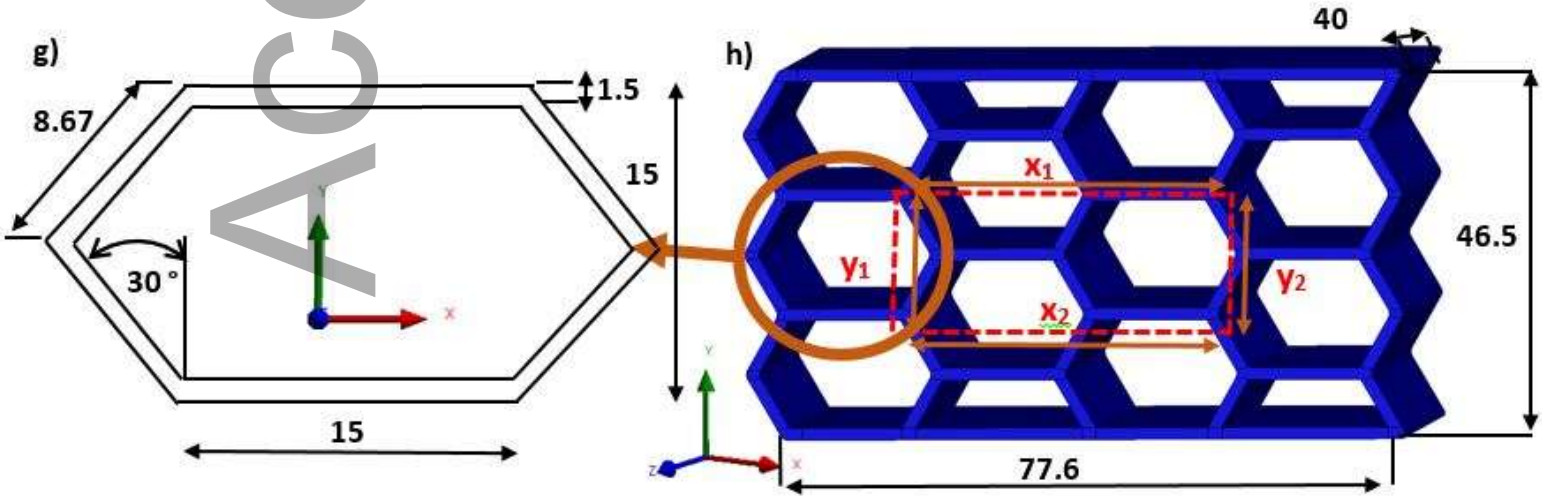

tetr

a

chir

al

unit

ric view of complete anti-tetra chiral lattice, e) 2D sketch of hound's-tooth unit-cell, f) isometric view of complete hound's-tooth lattice, g) 2D sketch of conventional honeycomb unit-cell and h) 


\section{WILEY-VCH}

isometric view of complete conventional hexagonal honeycomb lattice. All dimensions shown in $\mathrm{mm}$.

a)

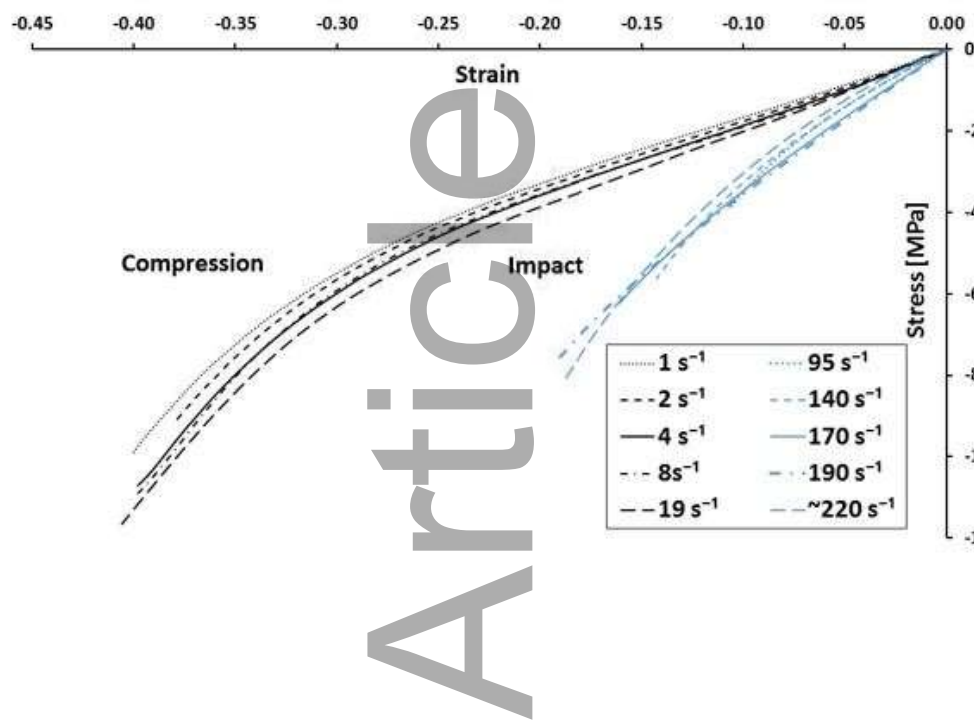

b)

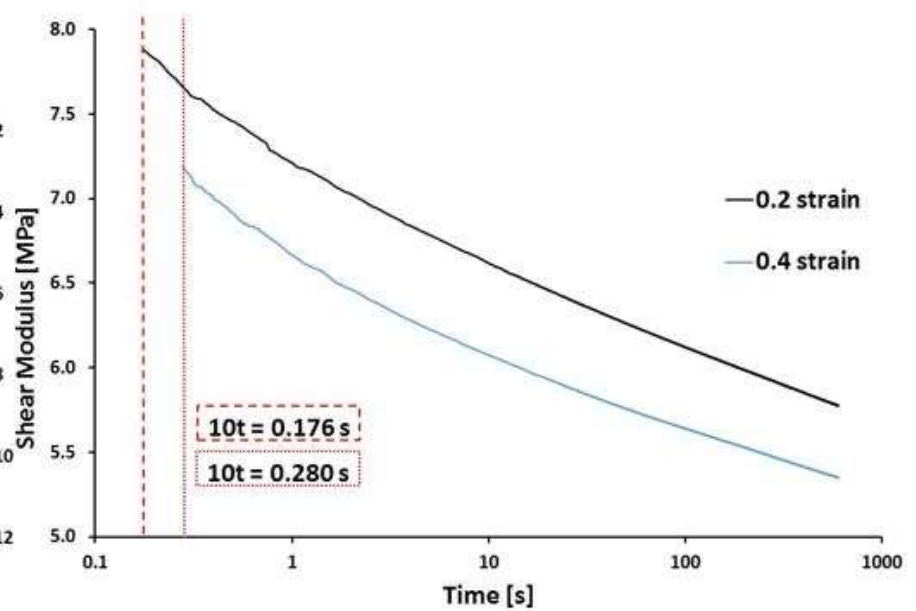

Figure 2. a) Stress $v s$ strain curves for a range of strain rates in compression (up to machine maximum of $\sim 19 \mathrm{~s}^{-1}$ ) and from impact testing (up to $\sim 220 \mathrm{~s}^{-1}$ ) and b) stress relaxation data for strain of 0.2 and 0.4 , with factor of ten rule applied and log scale used for time axis.

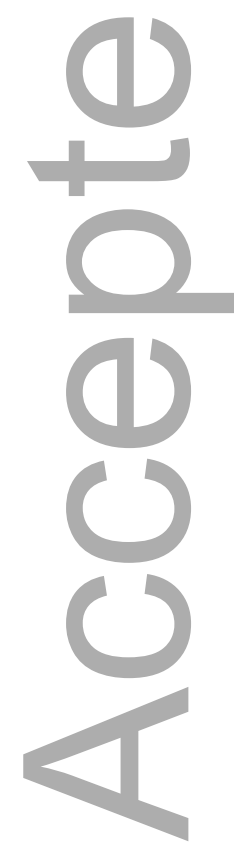

This article is protected by copyright. All rights reserved 


\section{WILEY-VCH}
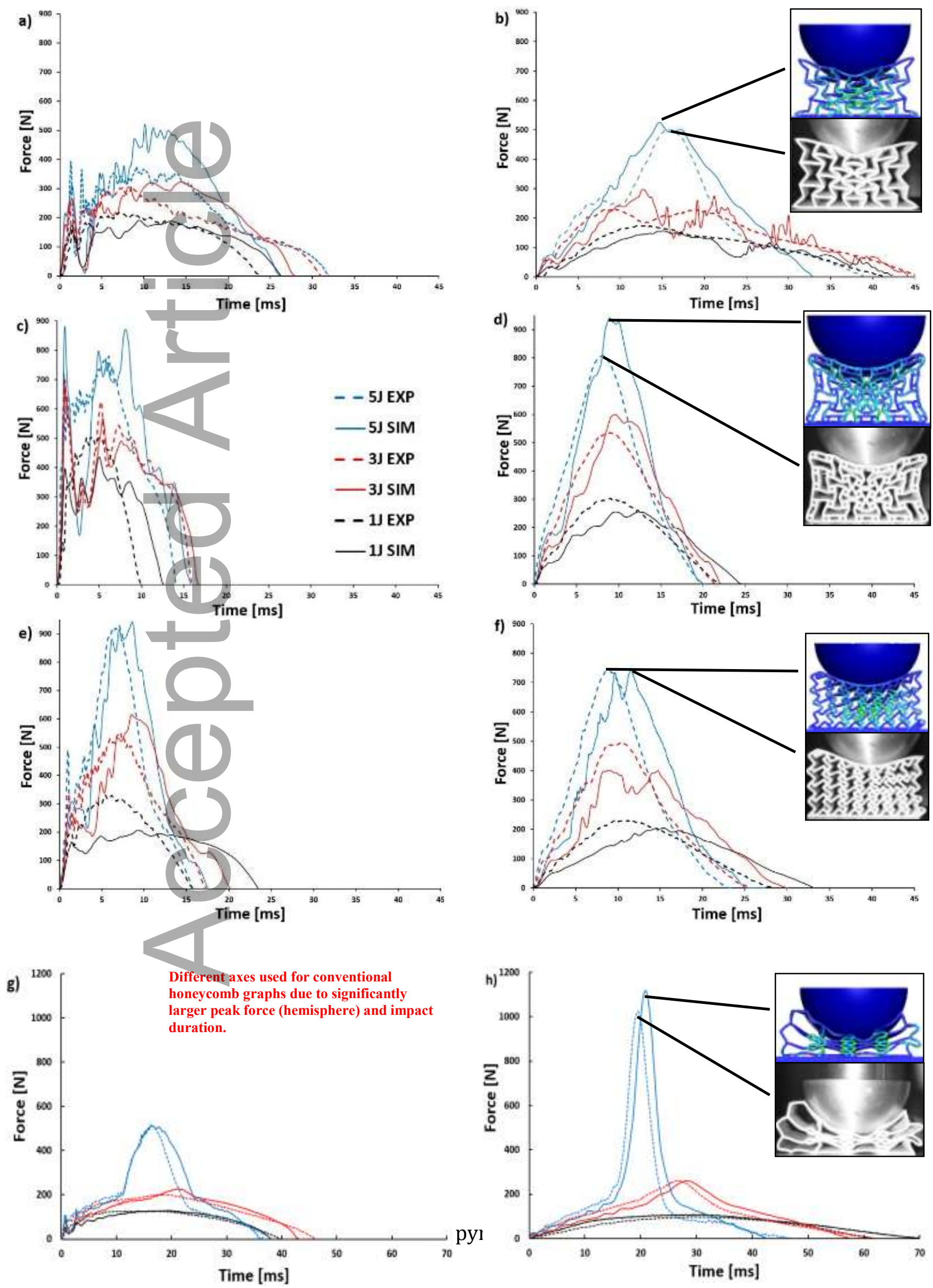


\section{WILEY-VCH}

Figure 3. Force $v s$ time graphs for auxetic lattices impacted at low, medium and high energies (1, 3 and $5 \mathrm{~J}$ ) - a) re-entrant_flat, b) re-entrant_hemisphere, c) anti-tetra chiral_flat, d) anti-tetra chiral_hemisphere, e) hound's-tooth_flat, f) hound's-tooth_hemisphere, g) conventional honeycomb_flat and h) conventional honeycomb_hemisphere. Images of maximum compression for $5 \mathrm{~J}$ hemispherical impacts are included to demonstrate densification of auxetic lattices in $\mathrm{b}$ ), $\mathrm{d}$ ) and $\mathrm{f}$ ) and 'bottoming out' of conventional honeycomb in $\mathrm{h}$ ).

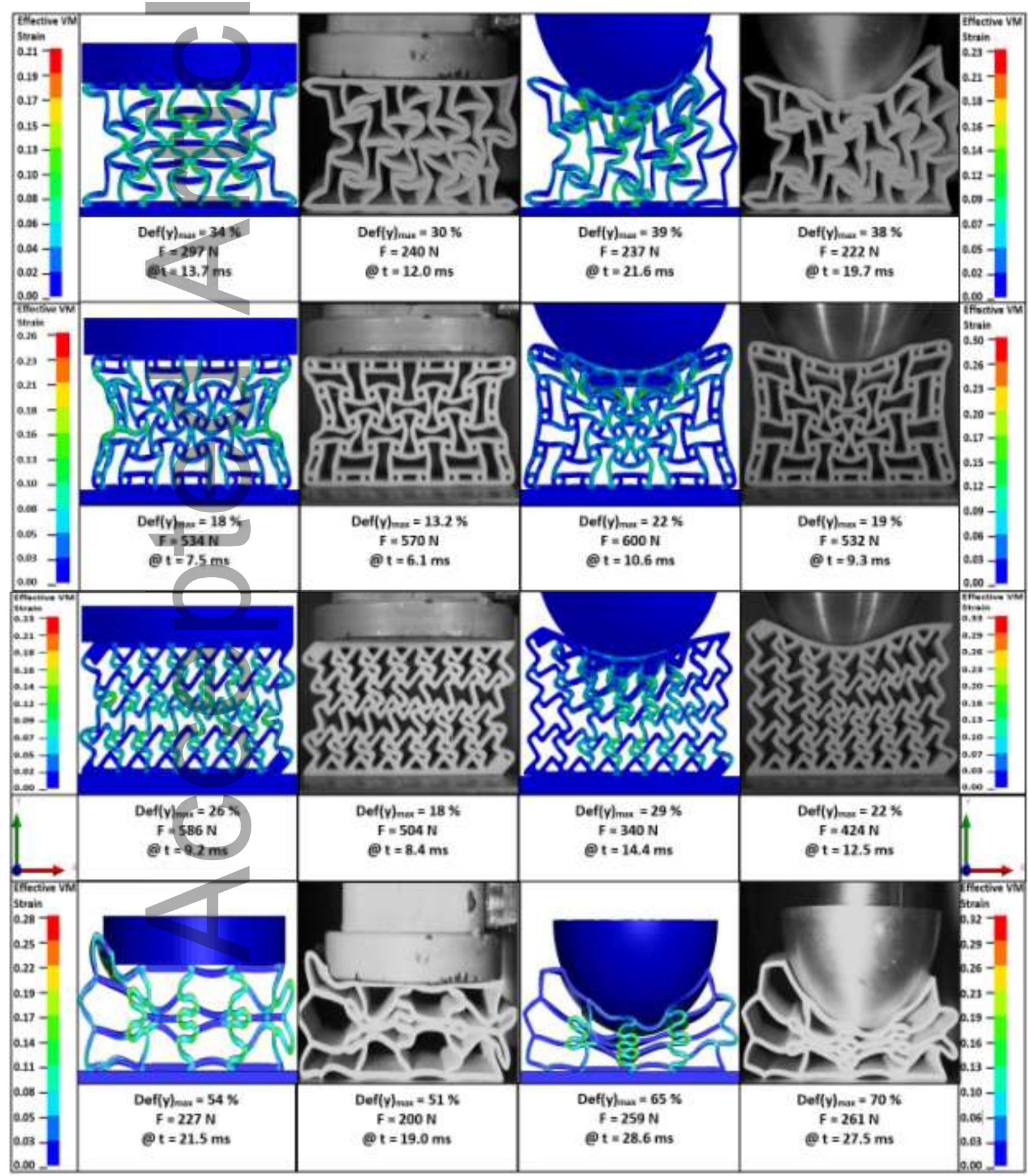

This article is protected by copyright. All rights reserved 


\section{WILEY-VCH}

Figure 4. Comparison images between simulation and experimental results at maximum compression of $3 \mathrm{~J}$ impacts, with key parameters recorded.

Table 1. Material model generated and used for TPU showing required parameters obtained from material characterization testing

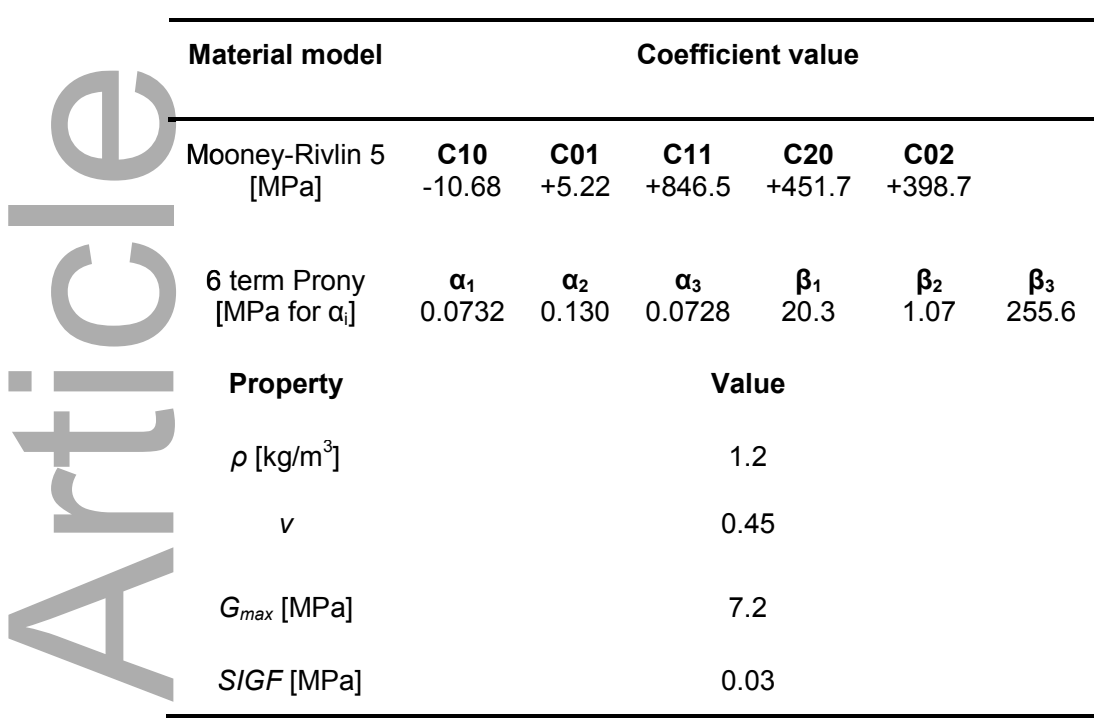

Table 2. Maximum predicted discrepancy for each key parameter, detailed per structure and hammer type, with the corresponding impact energy in brackets.

\begin{tabular}{|c|c|c|c|c|}
\hline Structure & Hammer type & Peak Force [N] & Axial strain difference & Impact duration [ms] \\
\hline $\mathrm{R} \epsilon$ & Flat & $118(5 \mathrm{~J})$ & $-0.06(1 \mathrm{~J})$ & $-5.6(5 \mathrm{~J})$ \\
\hline Re-en & Hemisphere & $63(3 \mathrm{~J})$ & $-0.06(1 \mathrm{~J})$ & $-9.0(1 \mathrm{~J})$ \\
\hline Anti- & Flat & $100(5 \mathrm{~J})$ & $0.05(3 \mathrm{~J})$ & $3.8(3 \mathrm{~J})$ \\
\hline Anti-te & Hemisphere & $131(5 \mathrm{~J})$ & $0.04(3,5 \mathrm{~J})$ & $2.7(1 \mathrm{~J})$ \\
\hline Hound's-tooth & Flat & $-122(1 \mathrm{~J})$ & $0.08(5 \mathrm{~J})$ & $7.8(1 \mathrm{~J})$ \\
\hline Hound's-tooth & Hemisphere & $111(5 \mathrm{~J})$ & $0.07(3 \mathrm{~J})$ & $5.1(1 \mathrm{~J})$ \\
\hline Conventional honeycomb & Flat & $28(3 \mathrm{~J})$ & $-0.02(5 \mathrm{~J})$ & $-2.2(3 \mathrm{~J})$ \\
\hline Conventional honeycomb & Hemisphere & $108(5 \mathrm{~J})$ & $-0.07(3 \mathrm{~J})$ & $-7.9(1 \mathrm{~J})$ \\
\hline
\end{tabular}

This article is protected by copyright. All rights reserved 

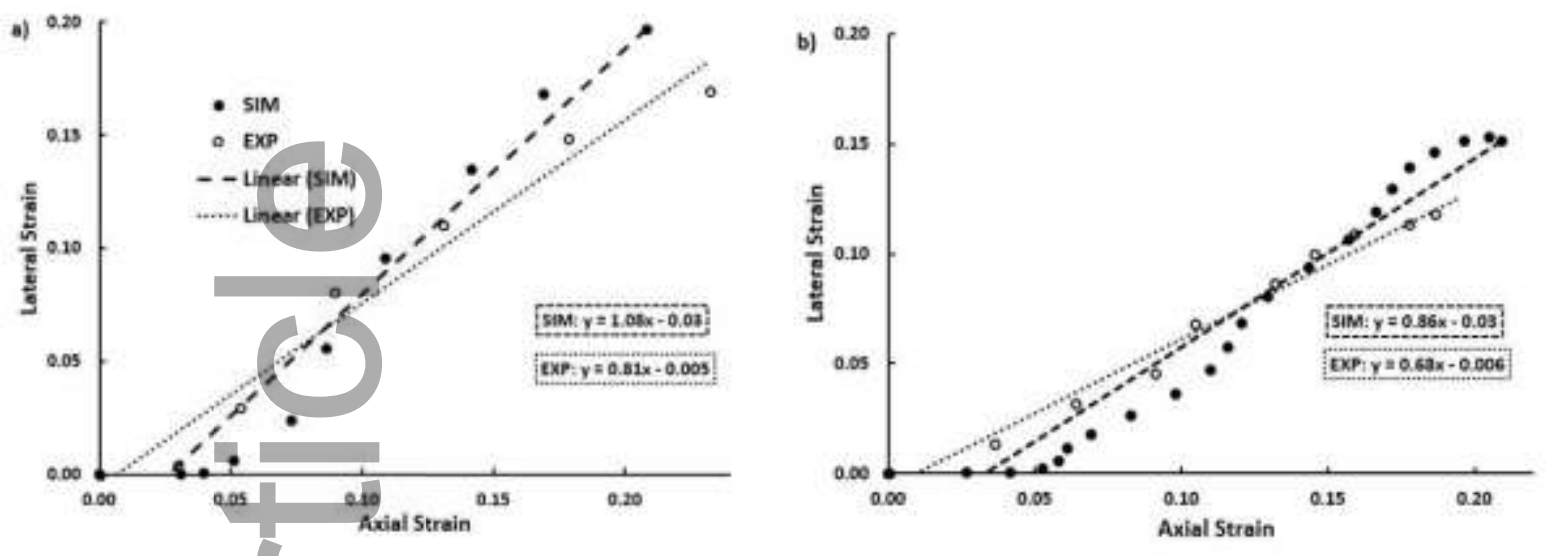

Fig

ure

5.

Lat

eral

vs

axi

al

stra

in,
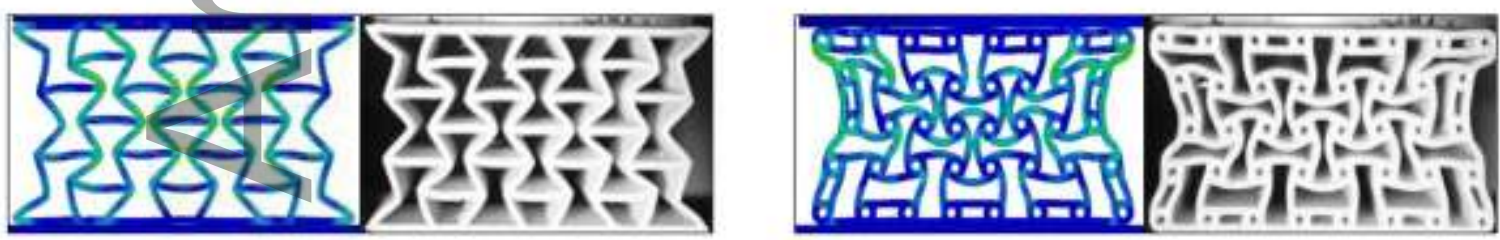

up

to

$\sim 0$.

2

stra

in

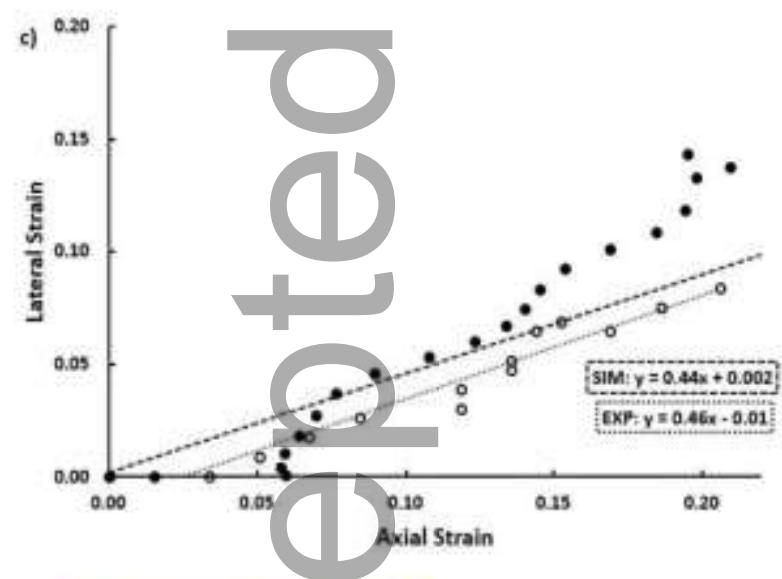

\footnotetext{
。
}

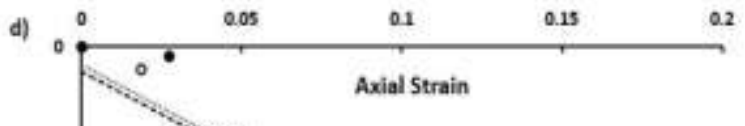

for

a)

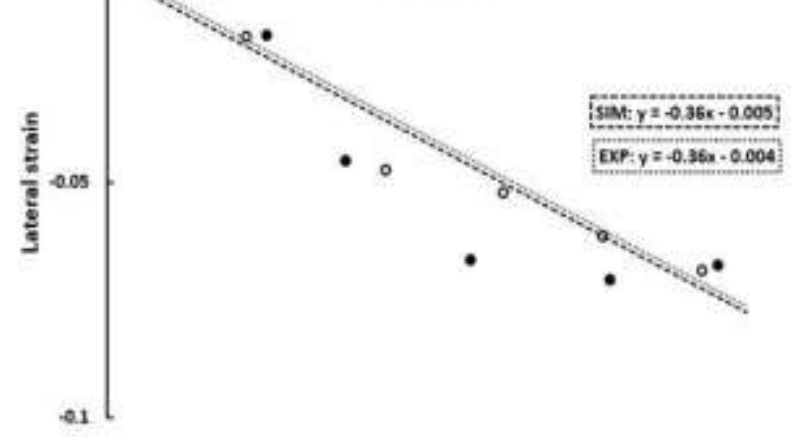

re-

entr

ant,

b)

anti

tetr

a

chir al,
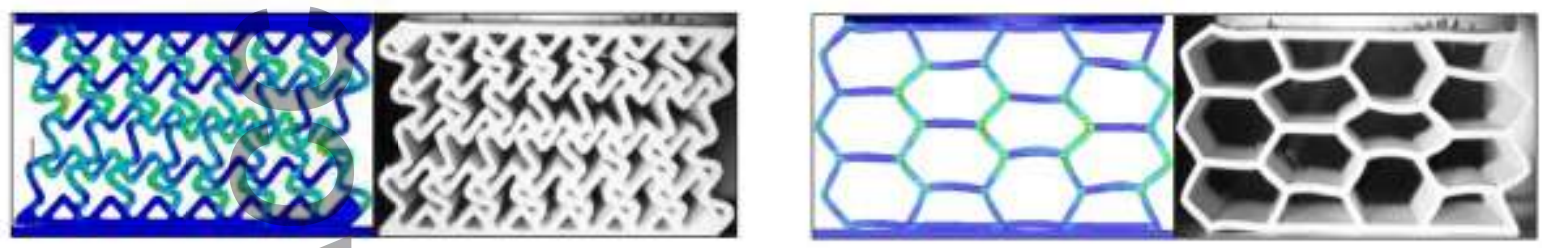

c)

hou

nd'

S-

toot

h

and d) conventional hexagonal honeycomb, with simulation and experimental images at $\sim 0.2$ strain included. Graphs are presented as positive strains and the negative of the gradient is equivalent to the Poisson's ratio. 


\section{WILEY-VCH}

ToC text:

A validated finite element model for three auxetic lattices and a conventional honeycomb lattice is presented. The lattices were additively manufactured and subjected to normal impacts of 1,3 and 5 $\mathrm{J}$, using flat and hemispherical drop hammers. The model can consequently be used as a design tool to advance the implementation of auxetic materials in sporting PPE.

ToC figure:

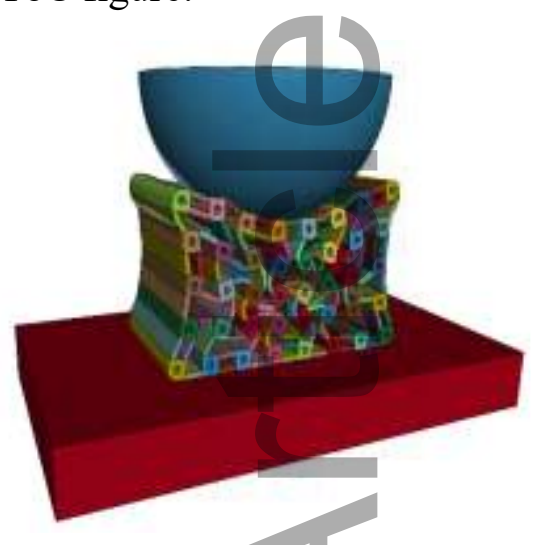

ToC keyword:

Auxetics

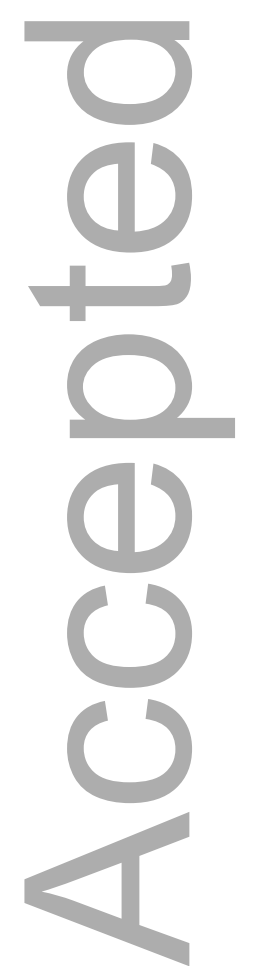

This article is protected by copyright. All rights reserved 